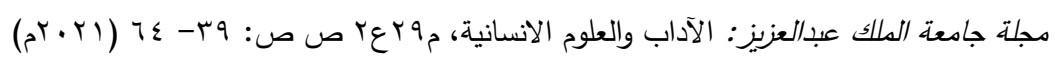

DOI:10.4197/Art.29-2.3

\title{
الرؤية النقدية لقصيدة المدح عند العقاد: بين التظير والتطبيق
}

\section{مصطفى محمد تقي الله بن مايابا}

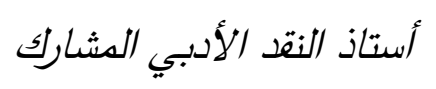

قسم اللغنة العببية وآدابها- جامعة الملك عبدالعزيز

مستخلص. يسلط البحث الضوء على طبيعة الانسجام بين رؤية العقاد المتأثرة بالتيار الرومانسي حول علاقة الأدب

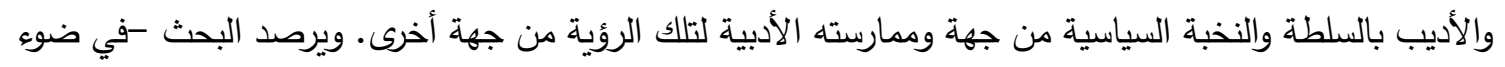

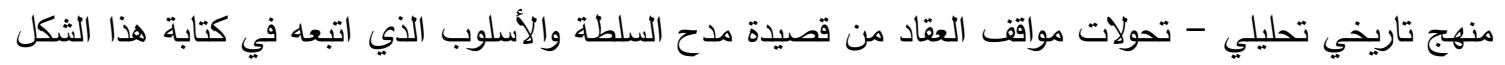

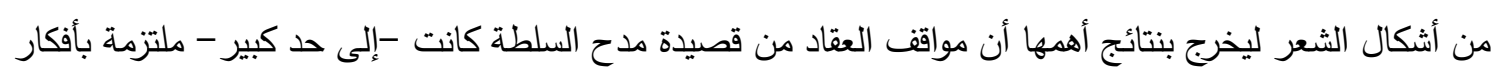

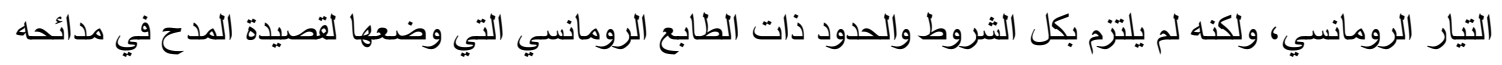

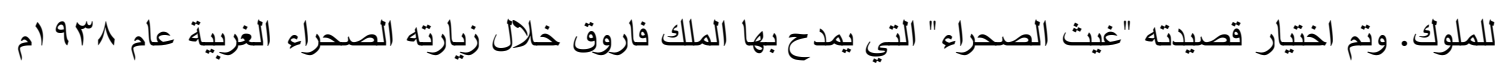

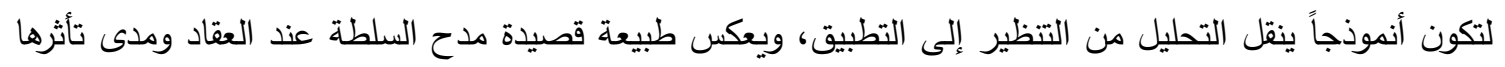

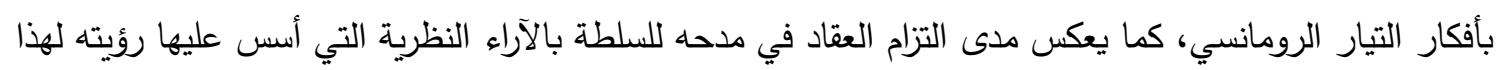

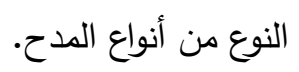
الكلمات المفتاحية: عباس محمود العقاد-السلطة السياسية-قصيدة المدح-الملك فاروق-الملك فؤاد الأولالرومانسية-الرومانسية الاجتماعية-الكلاسيكية.

على أسلوب التفكير الكلاسيكي الذي يمجّد العقل

\section{المقدمة}

تعد الرومانسية الأوروبية مرحلة مهمة من مراحل ويتجاهل العاطفة، ويقدم المنطق، ويؤخر الخيال،

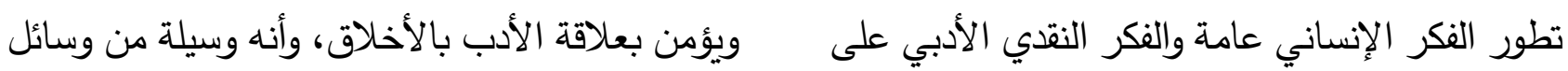

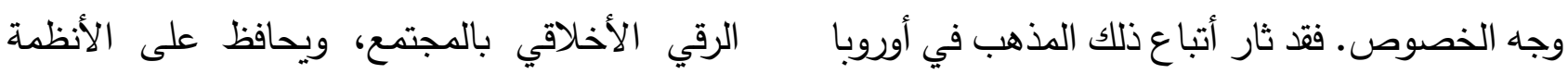


النظر الرومانسية النهائية للثورة ) (Ladd, 2010,

وفي الوقت الذي كانت تزدهر فيه الرومانسية في الفكر والأدب الأوروبيين في نهاية القرن الثامن عشر وخلال القرن التاسع عشر كان الأدب العربي يمر بمرحلة ركود يتلمس فيها الفكر الكلاسيكي طريقه بعسر ، قبل أن يتشكل على يد نخبة من الأدباء الإحيائيين في مقدمتهم محمود سامي البارودي (ت.ع • 9 (م) وأحمد شوقي (ت.rrو (م) وحافظ إبراهيم (ت.بrو (م) الذين تبنوا منهجاً يشبه في جوهره المنهج الكلاسيكي الأوروبي من خلال محاكاة القصيدة العربية القديمة. وفي فترة ازدهار ذلك الاتجاه الإحيائي بدأ مجموعة من الأدباء العرب في تبني أفكار التيار الرومانسي الأوروبي عامة والإنجليزي خاصة، وكان في مقدمتهم خليل مطران (ت.9 § 9 (م) الذي لم يرق له الأسلوب التقليدي في تأليف الشعر ، ولم يجد في أسلوب المبالغة الذي ترتكز عليه كثير من موضوعات القصيدة التقليدية أداة صادقة للتعبير عن ذاتية الثاعر، فذَّ المبالغة في الثعر وبخاصة شعر المديح حيث "صرح أنه يفضل في شعره الحقيقة، فإن عدل عنها في بعض مدحه فإنما يعدل ليكشف عما تسببه من نقائص في

$$
\text { الثعر" (سادات، ب99 } 99 \text { (م، ص77). }
$$

وتأثر عدد من النقاد العرب المعاصرين لخليل مطران في مطلع القرن العشرين بالحركة الرومانسية الأوروبية، وكان عباس محمود العقاد (ت.ء؟79 (م) من بين أولئك النقاد الذين استلهموا أفكار التيار
السياسية والاجتماعية والقوانين التي تحكم العلاقة بين طبقات المجتمع، ويُلزم الشاعر باتباع القواعد الشكلية التي تميز الشعر عن غيره من الكلام الأدبي وغير الأدبي وتميز أدب النخبة عن أدب العامة. فجاءت الرومانسية لتركز على الفرد وعواطفه من حب وألم ورغبات بصرف النظر عن الطبقة التي ينتمي إليها، ولترفع شعار "الإنسان أولاً"، وتطبق ذلك من خلال اعتمادها المطلق على العاطفة، وإطلاقها العنان للخيال دون قيود، ورفضها لربط الأدب بالأخلاق، وتمردها على الأنظمة السياسية والاجتماعية والقوانين التي تحكم تلك الأنظمة، ودعوتها لأن يمارس الثاعر حقّه في اختيار الشكل والمضمون اللذين يريدهما لقصيدته، وأن يكتب بلغة سهلة يفهمها المنتمون للطبقة الاجتماعية الدنيا بعيداً عن القوانين التي تحكم

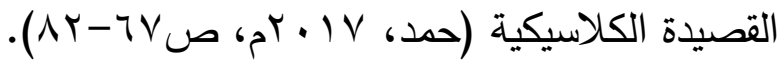
وظهر على إثر هذا الصراع بين الرومانسية والكلاسيكية في فرنسا مذهب يوصف بـ"الرومانسية الاجتماعية"، وبرز هذا المذهب خلال أربعينيات القرن التاسع عر • وسعت الرومانسية الاجتماعية بوصفها حركة شبه دينية- إلى الوئام في الوجود

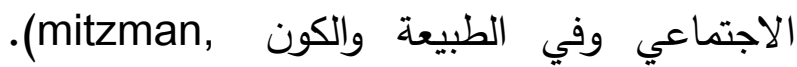
1999, p.86; Evans, 1951) كارليل (ت. INA1) على رأس هفكري هذا الاتجاه الرومانسي الاجتماعي، وذلك في كتابه تاريخ الثورة الفرنسية الذي كتبه عام VIN (م، وقدّم فيه وجهة 
الفرق بين مواقف العقاد النظرية من قصيدة مدح السلطة من جهة وأسلوبه في كتابة تلك القصيدة من جهة أخرى.

ويمكن التفريق بين مفهومين مرتبطين بالبحث: المدح وقصيدة المدح. فكل قصيدة مدح هي مدح، والعكس غير صحيح. وفي سياق الربط بين الرومانسية ومدح السلطة، فإن الأخير -في الغالب- هو خروج بالفكر عن الاتجاه الرومانسي، أما قصيدة المدح فهي خروج بالفكر والأدب معًا عن هذا الاتجاه. ومع أن العقاد يستخدم في بعض المواضع مصطلح "المدح" دون ذكر لكلمة "قصيدة" إلا أن السياق -في كثير من تلك المواضع- يدل على أنه يَعني قصيدة المدح، ويدل على ذلك استخدامه لكلمة "شاعر" في سياق حديثه عن المديح. ومفهوم "قصيدة المدح" المستخدم في البحث يشير إلى تلك القصائد التي تمجّد السلطة السياسية الحاكمة بعيداً عن القصائد التي يمدح فيها العقاد شخصيات ثورية معاصرة من مثل سعد زغلول

$$
\text { . (ت) } 9 \text { (ت. }
$$

ويعتمد البحث على المنهج التاريخي التحليلي من خلال تتبع تاريخي للمواقف التي سجلها العقاد في مؤلفاته المختلفة من قصيدة مدح السلطة، وتحليل تلك المواقف، وربطها بالمرحلة السياسية التي سُجلت فيها تلك الآراء. ويتلو ذلك وقفة موجزة على أسلوب العقاد في كتابة قصيدة المدح قبل تحليل قصيدته (غيث الصحراء) التي يمدح فيها الملك فاروق (ت.07 9 (م) بوصفها أنموذجاً يسلط الضوء على مدى التطابق
الرومانسي، وروّجوا له، ورفضوا نقيضها الكلاسيكي الذي يركز -في الغالب- على طبقة النخبة القريبة من السلطة السياسية دون غيرها من طبقات المجتمع. وقد رأى المازني أن يوميات العقاد كما كان ديوان شكرى "بداية اقتحام المذهب الجديد في الأدب للميدان، وفاتحة الصراع بينه وبين المذهب القديم، مذهب شوقى

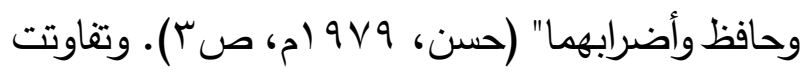
مواقف نقاد المذهب الرومانسي من أتباع المذهب الإحيائي، وتميز العقاد من بين أولئك النقاد بحدة مواقفه ضد الإحيائيين وخاصة شوقي، فانتقد منهجه، ورفض شعره، واتخذ قصيدة المدح عند شوقي -خاصة مدائحه السياسية للسلطة- مثالاً يستحضره في نقده المتكرر لشوقي من وجهة نظر رومانسية. وكان طبيعياً أن يختلف المذهبان الكلاسيكي الذي يركز على وظيفة الأدب الاجتماعية والرومانسي الذي يهتم بطبيعة الأدب في رؤيتها للأغراض الشعرية؛ فازدهرت قصيدة المدح عند الكلاسيكيين، وقلَّ رواجها بين الرومانسيين. ويسلط البحث الضوء على مواقف العقاد الفكرية والنقدية من قصيدة مدح السلطة؛ ليرصد تحولات موقفه من تلك القصيدة في مراحل حياته المختلفة، ويبحث عن الرابط بين تلك المواقف النقدية المبثوثة في كتبه من جهة وعلاقة العقاد بالسلطة السياسية في مرحلة تأليف تلك الكتب من جهة أخرى. كما يتضمن البحث تحليلاً لقصيدة العقاد (غيث الصحراء) التي مردي يمدح فيها الملك فاروق لتكون أنموذجاً شعرياً يوضح 
مراحل تمثل الحكومات المصرية التي عاصرها: تبدأ

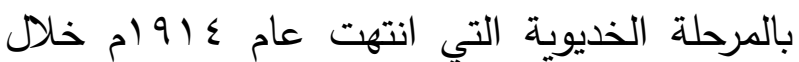
الحرب العالمية الأولى، ثم مرحلة فؤاد الأول

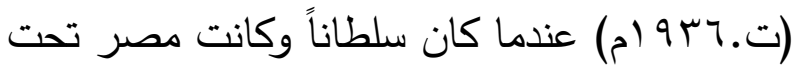

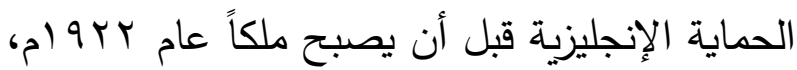
ثم مرحلة الملك فاروق (ت.970 (19)، وتتنهي بمرحلة الرئيس جمال عبد الناصر (ت. • צ9 ام).

ويمكن وصف المرحلة الخديوية في عصر العقاد بمرحلة "البناء" حيث عكف العقاد على تعليم نفسه، ولم تكن -في الغالب- مرحلة إنتاج وتأليف. وتشتمل المرحلة الثانية من حياة العقاد -في عهد فؤاد الأول-

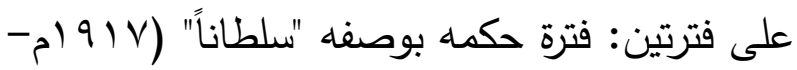

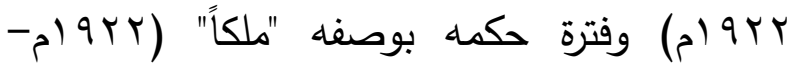
بـو ام). فقد برز العقاد في الحياة السياسية المصرية عام 9 19 ام في عصر السلطان فؤاد عندما شارك مع حزب الوفد بقيادة سعد زغلول في الثورة ضد حكم الإنجليز لمصر، وكان العقاد في تلك الثورة -كما يصفه أبو دية- "ممثلاً حقيقياً للطبقة الناشئة في مصر" (r...rم، صrه)، كما كان شاعر الثورة الذي يعبر عن طموح أبنائها. وفي المرحلة الثانية من

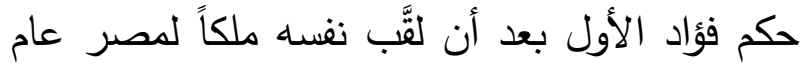
r 9 ام، اشتهر العقادُ بمعارضته لقرارات الملك فؤاد في البرلمان الذي رأسه سعد زغلول وعُيّن العقاد عضواً فيه عام 9 او ام، قبل أن يلقي فيه خطاباً معارضاً لمحاولة تعطيل العمل بدستور بr9 ام الذي صاغه مجموعة من قادة الأحزاب الثعبية. واتُهم على إثر لثري
والتباين بين مواقف العقاد النظرية من قصيدة المدح وأسلوبه في كتابة تلك القصيدة، وعلى مدى مطابقة قصيدته للنزعة الرومانسية الاجتماعية التي سيطرت -إلى حد كبير - على مواقفه النقدية من قصيدة المدح التقليدية. ويتكون البحث من ثلاثة أقسام: يتناول القسم الأول المعنون ب"العقاد والسلطة" بإيجاز علاقة العقاد بحكام مصر ، بينما يتناول القسم الثاني الموسوم بـتسلسل

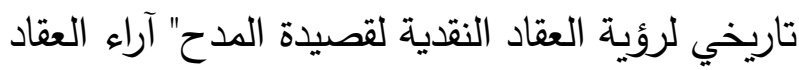

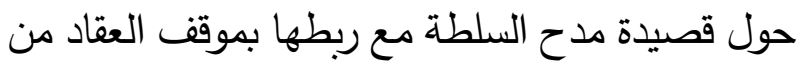
السلطة السياسية في فترة تسجيله لتلك الآراء، ويشتمل القسم الثالث الموسوم بـ"تحليل قصيدة اغيث الصحراء)" على تحليل لهذه القصيدة التي يمدح فيها العقادُ الملكَّ فاروق، ويسلط هذا القسم الضوء على مدى التزام العقاد في قصيدته بما شدّد عليه في آرائه النقدية حول قصيدة المدح.

\section{أولاً: العقاد والسلطة}

يُعد السياق السياسي من أهم العوامل التي شكلت رؤية العقاد النقدية حول قصيدة مدح السلطة. فقد وُلد بعد

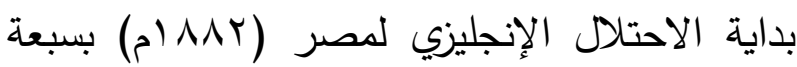

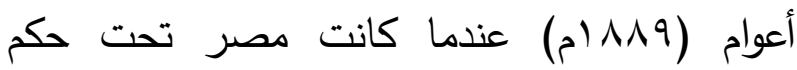
الخديوية. وتأثر في مطلع حياته بالاتجاهات السياسية والدعوات الثورية لتحرير مصر من الإنجليز ، وعاصر حكومات مختلفة، واختلفت مواقفه السياسية -بين المعارضة والتأييد- باختلاف هذه الحكومات. وفي هذا السياق السياسي يمكن تقسيم حياة العقاد إلى أربع 
يكتب قصيدة المناسبة بشتى أشكالها" (علوان،

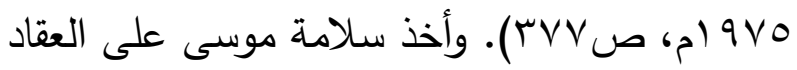

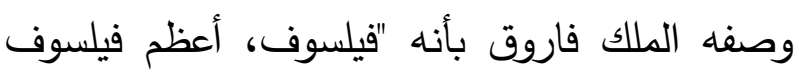
عرفه، كما لو كان [...] يشبه أرسطاطاليس أو

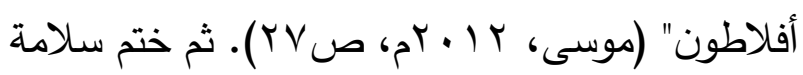
موسى هجومه على العقاد بقوله: "لقد أصاب كامل التلمساني، إن فؤاد ثم فاروق، قد أفسدا الأدباء والفنانين، وبدلاً من أن ينهضوا [العقاد وطه حسين]

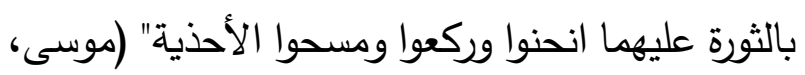

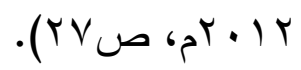

وبعد ثورة يوليو 90 ام على الملكية وزوال حكم الملك فاروق تحولت مواقف العقاد من الملك السابق، تورة

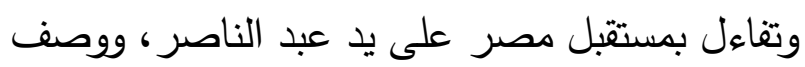
تحرر مصر من الاستعمار وتحولها السياسي بقوله: "فلم تمض من هذا القرن عشر سنوات متعاقبة دون

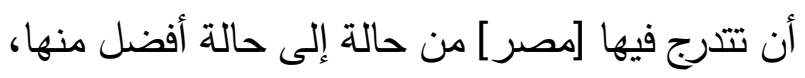
فخرجت من السيادة العثمانية، ثم خرجت من الحماية

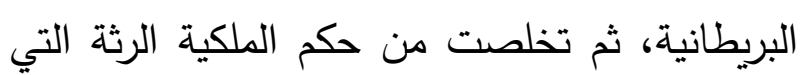

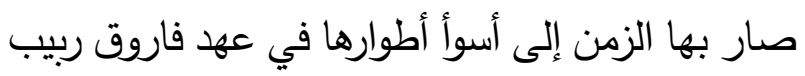
الفساد، ابن أحمد فؤاد صنيعة الحماية" (الإسلام في

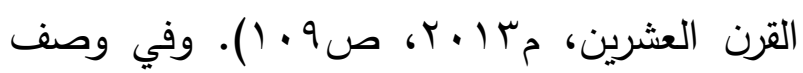
العقاد لفاروق ب"ربيب الفساد" بعد كل ما أنثده من

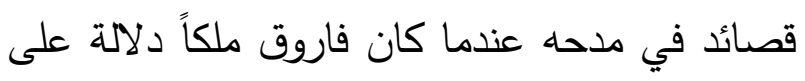

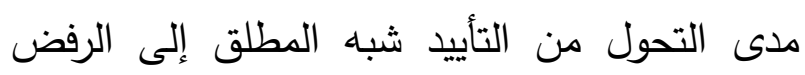
المطلق للملك السابق، ويمكن أن يُفسر هذا التحول على أن علاقة العقاد بالملك فاروق فسدت في نهاية ان فئر هائ
ذلك العقاد بتهمة "النيل من الذات الملكية" فُُجن

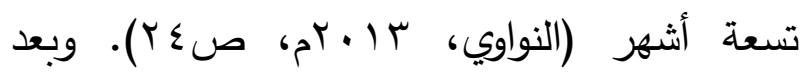

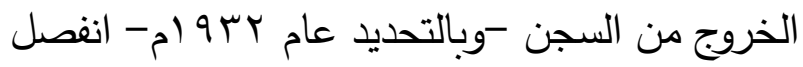
عن حزب الوفد. ثم بعد وفاة الملك فؤاد الأول عام

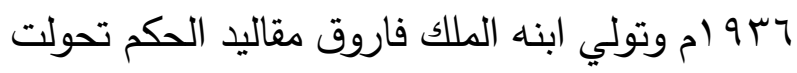
علاقة العقاد بالسلطة الحاكمة لهصر من علاقة البها المعارضة المطلقة إلى علاقة يغلب عليها التأييد والمناصرة. حاول العقاد أن يتقرب من الملك فاروق فمدحه بعدد من القصائد، وعينه فاروق عضواً في مجلس الثيوخ

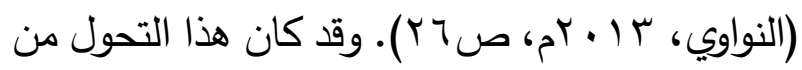
المعارضة المطلقة للملك فؤاد إلى التأييد شبه المطلق

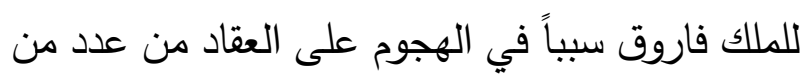

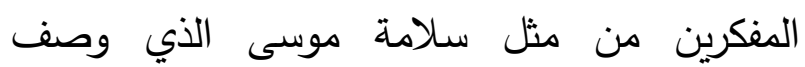
الاختلاف بين مواقف العقاد من الملكِين فؤاد الأول

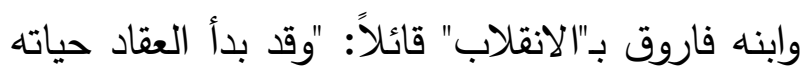
الأدبية بالسير مع الثعب، وكافح مع الزعيم العظيم

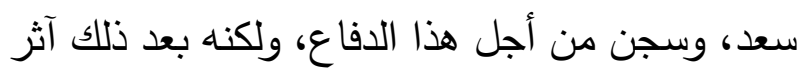
الملوكية على الشعبية، وكذلك فعل طه حسن حسن،

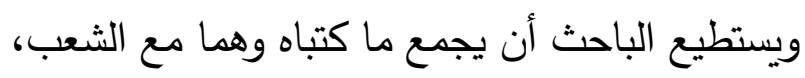
أيام ثورة 9 أوم، وما كتباه بعد ذلك حين أصبحا ملوكيين، ويقارن ويعلل هذا الانقلاب" (موسى،

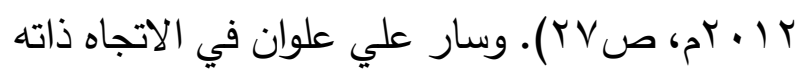
في انتقاده لتحولات العقاد حيث يقول "أما العقاد الذي الذي دعا الى تخليص الشعر من أغراض المناسبات بالمدح

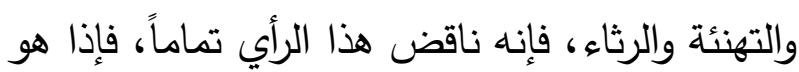


حاكماً مطلقاً. ويرى أن اختياره لرجاله ليس اختيارًا للموهبة أو الكفاءة [...] إنما هو يختار الذي يريحها،

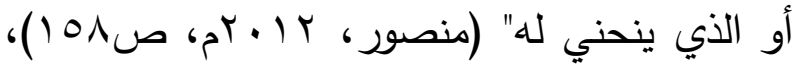
وكان العقاد يتهم الرئيس عبد الناصر بالغطرسة والغرور على الثعب الذي أوصله للحكم، ويدعو

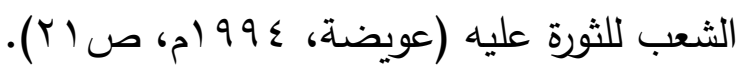
وهكذا، تغيرت علاقة العقاد بالسلطة السياسية التي

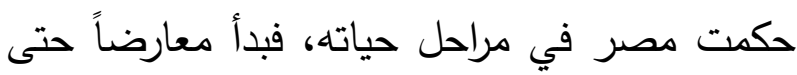

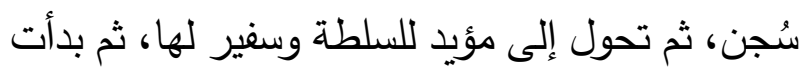
علاقته بالسلطة تضمحل وتجل حتىلى تحول إلى إلى معارض لها في نهاية حياته. وفي كل هذه المراحل

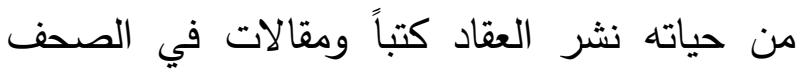
المصرية والعربية، وضمَّن كثيراً من تلك الكتب والمقالات آراءه الفكرية والنقدية حول علاقة الأدب بالسلطة، وفصّل وأجمل في رأيه حول مدح الثاعر

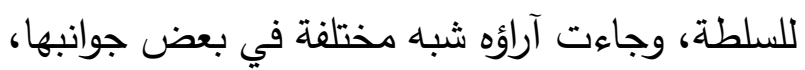
وهو ما يجعل التساؤل حول علاقة مواقفه النقدية من لن قصيدة مدح السلطة بمواقفه من السلطة في تلك الفترة

تساؤلاً منطقياً.

ثانياً: تسلسل تاريخي لرؤية العقاد النقدية لقصيدة المدح عكست آراء العقاد النقدية -إلى حد كبير - أفكاره

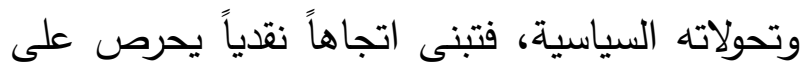
التعبير عن الذات الثاعرة بعيداً عن موضوعات لفئاتيات الشعر التقليدية التي يمدح فيها الثاعر أميراً ويرثي لتئي آخر ، ويصف فيها انتصارات المدوح على خصومه.
حكم الملك أو أنه كان يخفي في نفسه ما يناقض المدح والثناء للملك في شعره أو أنه أراد أن يتقرب من فن النه الرئيس عبد الناصر من خلاء البراءة من أي ولاء سابق للملك فاروق. وقد سيطر الثك على علاقة العقاد بالسلطة السياسية في مرحلة حكم الرئيس جمال عبد الناصر، فأيد الثورة ولكنه -في مرحلة لاحقة- لم يؤيد جمال عبد الناصر تأييداً مطلقاً. و أشار هيكل إلى "أن الرئيس [جمال

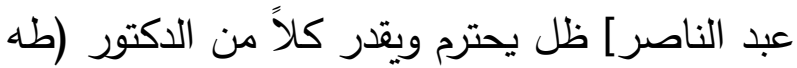

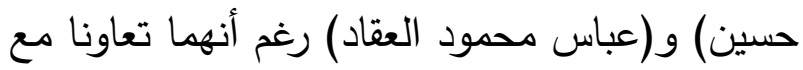

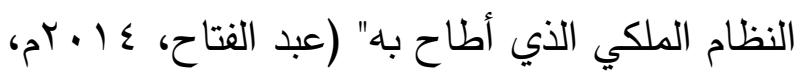
ص VV). ويعقِب عصام عبد الفتاح على ذلك بقوله: "ولعل هذا مردود عليه [هيكل] بأنه وإن كان النظام الناصري بالفعل لم "يعاقب" عملاقي عصر النهضة (طه حسين) و(عباس العقاد) بسبب سابق تعاملهما مع النظام الملكي لكنه في المقابل تعامل معهما بجفاء

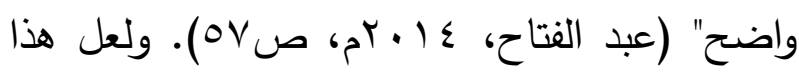
الجفاء من الرئيس عبد الناصر تجاه العقاد كان سبياً

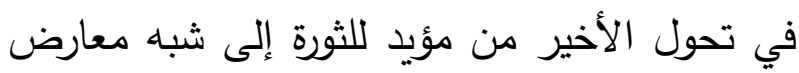
للرئيس. ومن أدلة معارضته في آخر عمره لعبد لعديد

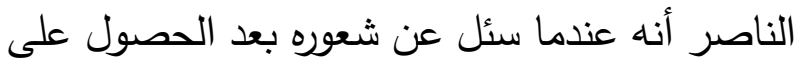

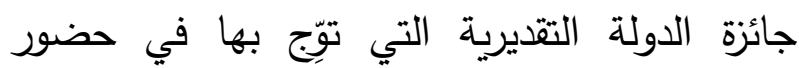
عبدالناصر أجاب "إنه شعور بالامتنان. فهذه الجائزة أخذتها من الشعب على يد الحكومة!" (منصور ، بابل

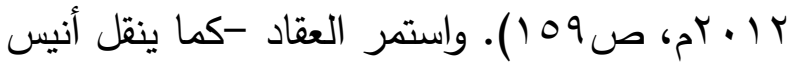
منصور - "ينتقد الرئيس جمال عبد الناصر، ويرى فيه 
ابr9 ام -بمشاركة إبراهيم المازني خلال مرحلة ثورة 9 19 (م- حرصه على الشهرة، وتكسبه بشعره، فهو "لا يمدح الناس إلا مأجوراً" (9 1 • بم، صبr). وكرر موقفه الرافض لشعر المناسبات والمدح عند شوقي في أكثر من موضع ومن كتاب، كما في قوله: "تقرأ مائة قصيدة لشوقي ولا تستخرج منها 》ملامح شخصية《 غير ملامح المبدع الصناع. ولهذا يمدح شوقي من مدحهم ويرثي من رثاهم وهم عشرات من مختلف الأعمال والأدوار ، ولا تكاد تميزهم من شعره بغير ما ميزتهم به الأسماء والأرقام والعناوين" (دراسات في

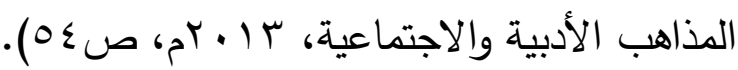
ورفض العقاد في الديوان تقليد الشعراء المعاصرين من الذين لم يعرفوا البادية والصحراء كشعراء مدرسة الإحياء للشاعر العربي القديم في رحلته الثعرية في الفيافي إلى الممدوح دون تجديد، حيث "نشأ من شعراء الحضر جيل كان أحدهم يقصد الأمير في المدينة، وإنه لعلى خطوات من داره، فكأنما قدم عليه من تخوم الصين لكثرة ما يذكر من الفلوات التي اجتازها، والمطايا التي أضناها، وحقوق الصبابة التي قضاها" (9 1 • (rم، ص Vץ). كما انتقد العقاد في الكتاب ذاته بعض معاصريه من الشعراء المقلدين في افتتاحهم لقصيدة المدح بالمقدمة الطللية، وسخر من شوقي بوصفه مثالاً لأولئك الشعراء - قائلاً: "الآن وقد بادت الطلول والقصور، ونسخت آية المديح بمطالعه ومقاطعه، وتفتحت للقول أبواب لم تخطر لأحد من المتقدمين على بال [...] يجيء شوقي فيتماجن
وكما يلاحظ كامل عويضة فقد "تغيرت خريطة الأولويات فى الموضوعات الشعرية عند العقاد بالقياس إلى الموضوعات التقليدية التى عرفها ديوان الشعر العربى قبله أو عرفها معاصروه، وكان من الطبيعى أن تضمر بعض الموضوعات ذات الطابع الاجتماعي، أو الوطني المباشر والموضوعات الاحتفالية [...] وكان من الطبيعي في مقابل ذلك أن تأخذ الموضوعات الذاتية مكاناً بارزاً" (عويضة، צ9 أم، ص (V). ويمكن -في سياق تحولات العقاد الفكرية- تتبع تحولات مواقفه من مدح السلطة في ضوء التسلسل التاريخي لتلك المواقف، بدءاً من كتاب الديوان الذي يُعد أحد أعماله النقدية المبكرة، وانتهاء بآرائه التي سجلها قبل وفاته بعام. بدأ العقاد إنتاجه النقدي في عصر السلطان فؤاد الأول عندما كانت مصر تحت الحماية البربطانية برؤية تجديدية تدعو لأن يكون الأدب تعبيراً عن الإنسان وعواطفه، واتبع اتجاهاً رومانسياً يرفض التزام الشعر بالموضوعات التقليدية التي تتوارى فيها شخصية الأنا الشاعرة، وتظهر فيها شخصية الآخر كما يُلحظ في شعر المدح. ومن هذا المنطلق، بدأت خصومة العقاد لشوقي الذي يمثل -في رؤية الأول - أنموذجاً للشاعر التقليدي الذي يتجاهل ذاته ليصور ذوات الآخرين، ويسخِّر قصيدته لمدحهم. وحاول العقاد أن يؤسس لمذهبه من خلال نقضه لشاعرية شوقي الذي يرمز لاتجاه أدبي كلاسيكي يمثل الطبقة الأرستقراطية في المجتمع، فأخذ عليه في كتاب الديوان الذي صدر عام 
عندما كانت الاتجاه الكلاسيكي مسيطراً على الأدب، "حتى أدركته بوادر الثورة الفرنسية، فانتثله من سقوطه

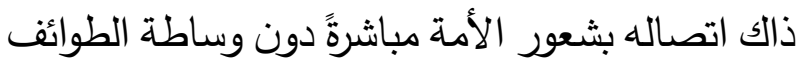

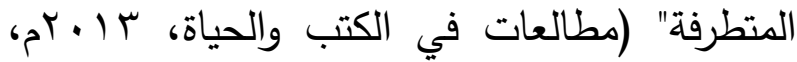
صץr). فقد كان ذلك الأدب على وشك السقوط بسبب طبقة السلطة قبل أن ينقذه المجتمع من خلال الثورة. ويقدّم العقاد مثالاً آخر يتمثل في الأدب الإنجليزي قبل أواسط القرن التاسع عشر الذي كادت التاد أن تلحقه عيوب الأدب الفرنسي، "لولا أن ثورة الثعب التبل

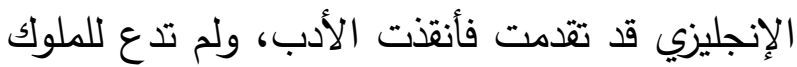
والنبلاء سبيلاً إلى أن يتحكموا في الشعر والكتابة كل التحكم، ويجعلوهما وقفًا على أذواقهم وشهواتهم، فكان التهان له من ذلك بعض العصمة والمناعة" (مطالعات في

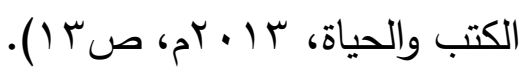
وتحدث العقاد عن المدح في كتابه مراجعات في

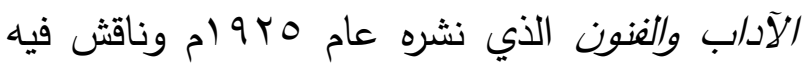

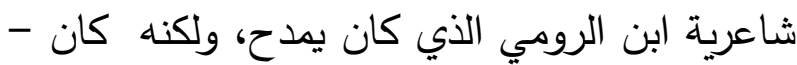
كما يرى العقاد - يصور رؤيته للحياة في قصيدته، وقد الدي اختاره ليقارن بين المادح الكلاسيكي الناظم -من مثل بعض شعراء الإحياء- الذي يقلد أسلافه وجنس آخر آلران من الثعراء وصفه العقاد بأنه "يستوحي نفسه وينظر إلى الدنيا حتى في قصائد الددح التي نعدّها أخلى الثى الكلام من أغراض الثعر ومعاني الحس وبدائع النظر النّات

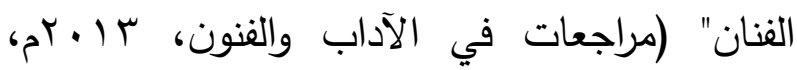
صبr • (). ثم يشني العقاد على مدائح ابن الرومي

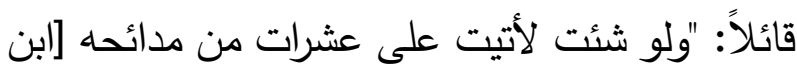

ويتصابى في مطلع قصيدة، يتظر بها مستقبل أمة "

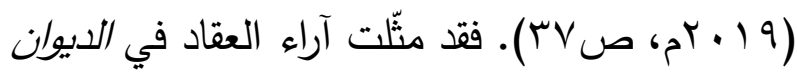
رؤيته النقدية الأولى في مرحلة تأثره العميق بالفكر العاد الرومانسي. وبعد أعوام من نشر الديوان -وبالتحديد في عام צ 9 ام بعد أن أصبح فؤاد الأول ملكاً لمصر - تناول العقاد في كتابه مطالعات في الكتب والحياة (ع بـ 9 (1) العلاقة العكسية بين رقي الأدب والحرص على إرضاء طبقة السلطة بذلك الأدب. فكلما حرص الأدب على الكى الكاب إرضاء السلطة كلما ضعف وانحط، وكلما اقترب من الابن

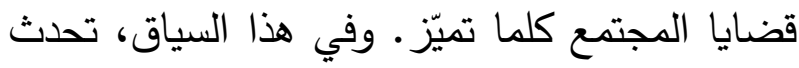
العقاد في مطالعاته عن سبب هبوط الثعر في التاريخ العربي، وأرئخ لذلك بأواسط العصر العباسي عندما أصبح "الأدب هدية تُحمل إلى الملوك والأمراء لإرضائهم وتسليتهم ومنادمتهم في أوقات فراغهم" لالإن

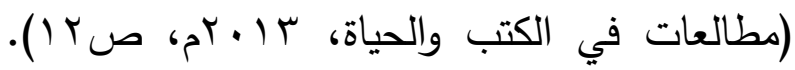

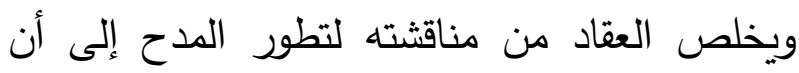
"انحطاط الآداب في جميع اللغات، إنما كان يبدأ في عصور متثابهة هي في الغالب العصور التي يعتمد فيها الأدب على إرضاء طائفة محدودة، يعكف على فئل فئل

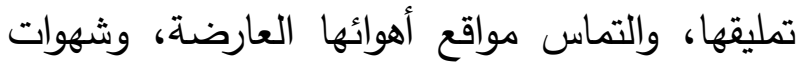

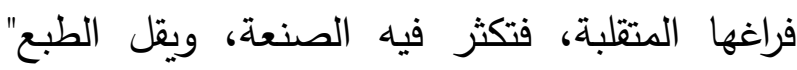

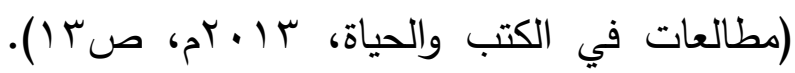
مثال ذلك الأدب الفرنسي الذي ضعف -في نظر

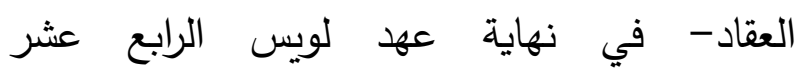

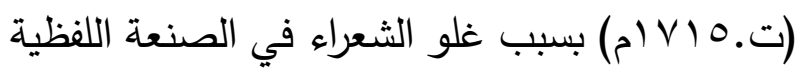


فيه بين الجد والسخرية. وذكر العقاد في هذا الكتاب أنه عرف من أحد النقباء في السجن الكثير عن لعن

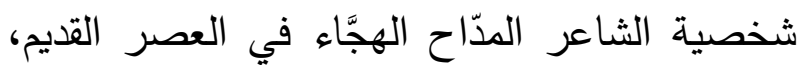

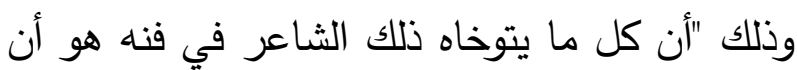

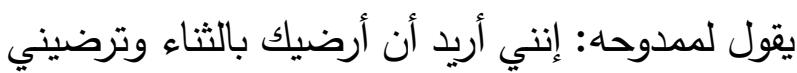
بالعطاء، وهي صفقة معقودة علانية بعلم المادح والمددوح والسامعين، لا حاجة فيها إلى الصدق، ولا إلى المعاشرة، ولا إلى الإخلاص، ولا إلى شيء غير البضاعة والثثن، والبضاعة هي المدح الظاهر، والثمن هو العطاء الظاهر" (عالم السدود والقيود،

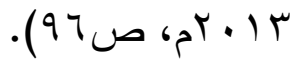
ويتضح من الآراء السابقة أن العقاد لم يكن من المؤيدين لقصيدة المدح التقليدية، وكان من الرافضين لثكلها القديم الذي يعتمد على ثلاثية الوقوف على الثى الطلل ثم الرحيل ثم المديح، وعاب شوقي على تكسبه بالثعر ، ووضع معيار الذاتية وبروز شخصية الثاعر أساساً لقبول قصيدة المدح. وفسر العقاد انحطاط الآداب بأنه نتيجة لحرص الأدباء على إرضاء طبقة

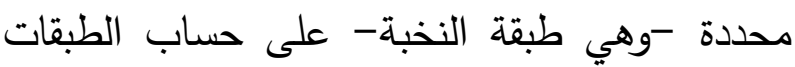
الأخرى، كما آمن بدور المجتمع في نهضة الأدب، وعبّر عن هذا الدور بما حصل في الثثرتين الفرنسية والإنجليزية من نهوض للأدب على يد الشعب بعد أن أوشك على السقوط بسبب النخبة السياسية. وتعكس هذه الآراء -إلى حد كبير - نزعة رومانسية سيطرت على العقاد في مرحلة ما قبل دخوله السجن.
الرومي] كلها تصلح للاستشهاد بها في هذا السياق" الاقداق

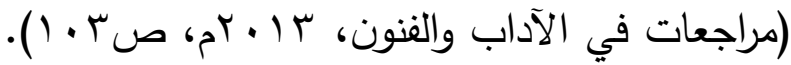
فالعبرة -في رأي العقاد- ببروز ذاتية الشاعر في المدح. وتحدث العقاد عن رؤيته للعلاقة القديمة بين المادح والمدوح في كتابه /بن الرومي: حياته وشعره الذي

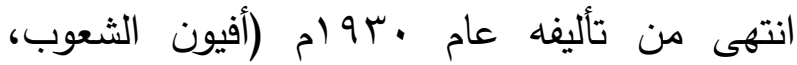
r (. r، ص • (1)). ويرى فيه العقاد أن أواخر عصر ابن الرومي الذي "كان يكذب حين يمدح ويتوسل" لوبل

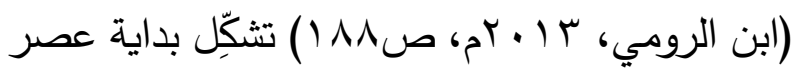
التحول من التكسب بقصيدة المدح إلى كساد تلك المهنة، وكان هذا التحول -في رأي العقاد- نتيجة لعوامل منها "قلة الاكتراث للمدح والذم حين استبحر

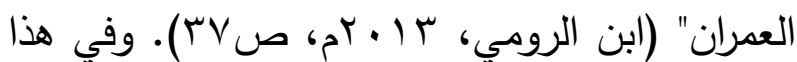
السياق قارن العقاد بين غضب الثاعر في عصر ابن الرومي من جهة وغضبه في العصر الحديث من جهة

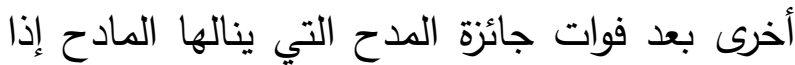

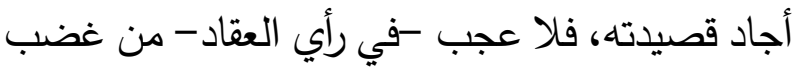
الأول ولا اعتراض؛ لأن "الحكم عليه إنما يكون بمقياس

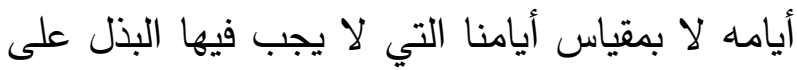

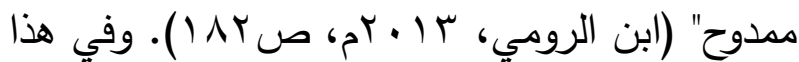
إشارة إلى رفض العقاد لفكرة طلب المال أو الجائزة مقابل المدح في العصر الحديث. وكرر العقاد رؤيته حول العلاقة بين المادح والمدوح ولكن بأسلوب ساخر في كتابه عالم السدود والثقيود الذي ألّفه بعد الخروج من السجن عام اسبو ام، ومزج 
العقاد في رأيه المتسامح مع التكسب بالثعر من رؤية رومانسية تؤمن بحرية الفنان وتفرق بين معيد بياري

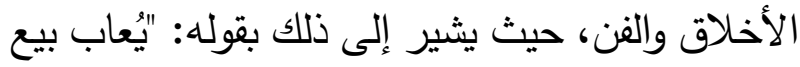
الثناء من وجهة الخلق والعرف لا من وجهة الفن والتعبير، أما الذين 》يقلدونه في إنكار القديم فقد وجن

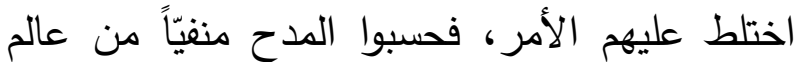
الشعر لذاته لا لما قدمناه" (ديوان وحي الأربعين،

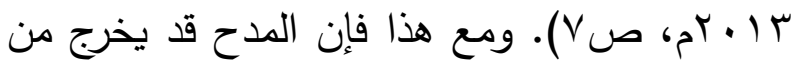

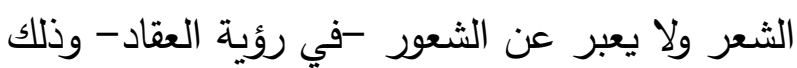

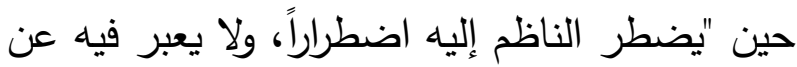

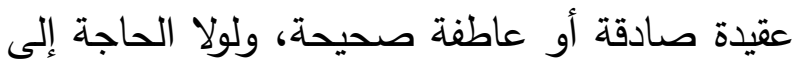
نوال الممدوح لما نظمه ولا أجاله في خاطره، فمن هنا

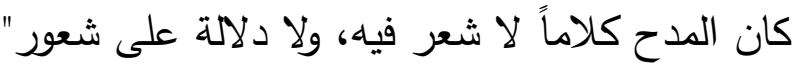

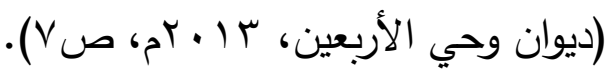
واستمر موقف العقاد المتسامح مع قصيدة المدح في كتابه شعراء مصر وبيئاتهم فى الجيل الماضي الذي

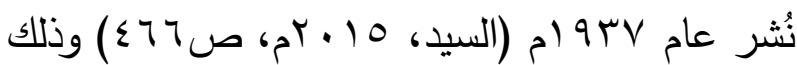
بعد وفاة الملك فؤاد الأول واختيار ابنه فاروق لخلافته، حيث لم يقف العقاد في ذلك الكتاب من قصيدة المدح عند حافظ إبراهيم موقفه من نظيرتها عند قرينه شوقي، بل امتدح قصيدة حافظ لأنه كما يقول: "يمثل أمته في لئي مديحه كما يمثلها في قصائده الاجتماعية، فهو مديح يدل على مراحل الأدب والحرية القومية في الأمة المصرية مرحلة بعد مرحلة، وبهذه الخصلة أيضاً كان

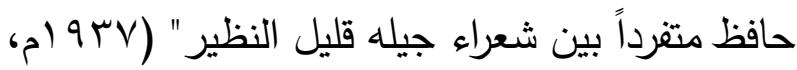
ص9 (1). واستمر العقاد في رؤيته المتسامحة للمدح
ويمكن رصد بوادر تسامح العقاد مع فكرة المدح في مرحلة ما بعد خروجه من السجن ثم انسحابه من حزب الوفد وذلك قبل تولي الملك فاروق للسلطة بأعوام. فقد أشار في مقدمة ديوانه وحي الأربعين الذي أصدره عام بام بامون بr9 ام إلى تفريقه بين شكلين من أشكال المدح،

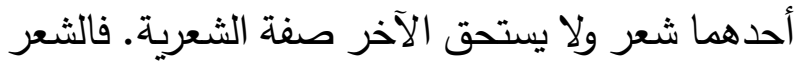
-في وجهة نظر العقاد- "لا يكون عصرياً مبتكراً لأنه خلا من المدح، ولا يكون قديماً محكياً لأنه يشمل عليه"

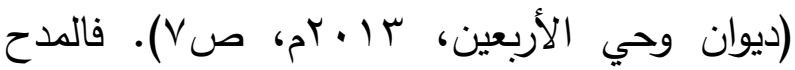
غرض شعري مثل غيره من أغراض الثعر التي تبرز فيها شخصية الثاعر ، و -كما يرى العقاد- ف"المادح الذي يقول ما يعتقد أو يحس أو يتمثل أو يتخيل فلا فرق بينه وبين شاعر الوصف والغزل والحماسة من

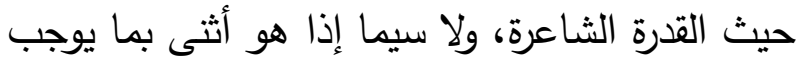
الثناء في رأيه وضميره" (ديوان وحي الأربعين،

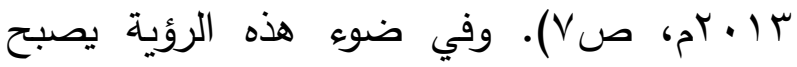

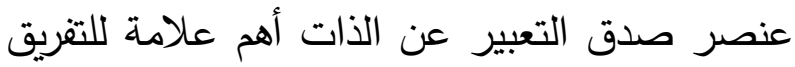
بين الشعر الكلاسيكي ونظيره العصري. ويذهب العقاد في مقدمة ديوانه وحي الأربعين مذهباً أكثر تسامحاً مع التكسب بالمدح حين يصور المادح المتكسب بشعره كالمصور الذي يتكسب بريشته أو الفنان الذي يُطلب منه "أن يجيد نقل الثبه والدلالة على الملامح والأطوار النفسية، فإن أجاد في عمله هذا فهو مصور كأحسن المصورين، وإن لم يجد فليس

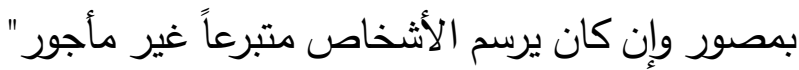

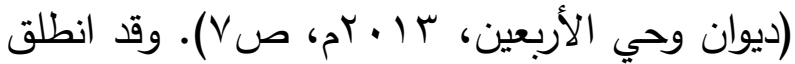


وكرر العقاد آراءه حول قصيدة الددح وارتباطها بحال الأمة في كتابه ساعات بين الكتب الذي ألفه عام

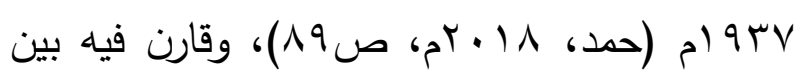
المدح في الآداب العربية الذي تغلب عليه -في وجهة أنها نظره- الفردية ونظيراتها الأوروبية الذي تسيطر عليه النزعة الاجتماعية. وفي ضوء ثنائية المدح الفردي

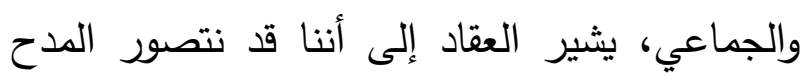
الفردي حين "تكون العلاقات الفردية هى الغالبة، والمدائح الفردية هى المطلوبة، ولكننا لا نتصوره حين تتشأ للتكاليف المدنية علاقات، ولباقات، وآداب، تترقى بصناعة التتويه والمدح من هذه السذاجة إلى لى

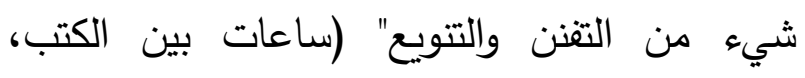

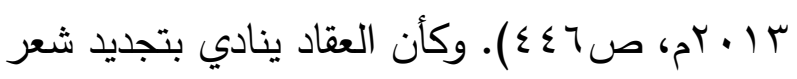

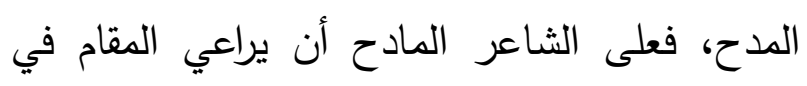

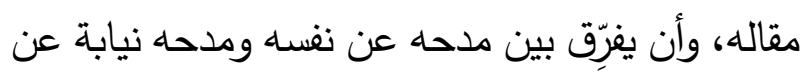
الأمة، ويصور العقاد ذلك في قوله: "فإذا وقفت أنا

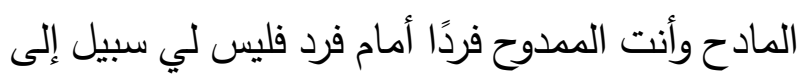
غير الثناء على شخصك وتمليق سمعك، وإعلان شكرك، ولكني إذا وقفت أنا شاعر الأمة أمام أمير وتماء

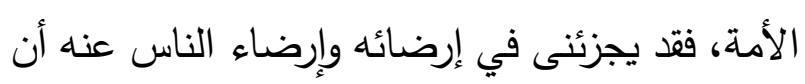
أعلن فخار الأمة، وأجعله هو مناط ذلك الإعلان، إنهان

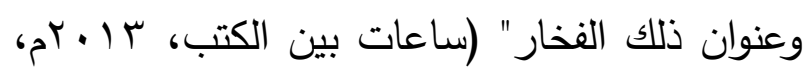

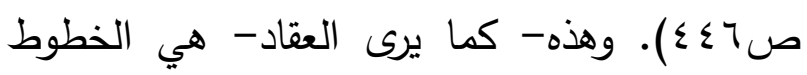
العريضة التي تفرق بين المدح العربي والمدح الإنجليزي الأوروبي.
حين أكّد فكرة التفريق بين المدح الذي يخدم الأمة

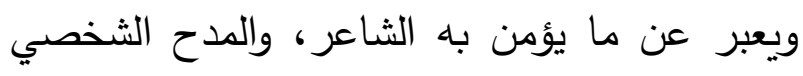
الذي يستجيب فيه الثاعر لرغبته الخاصة، حيث بيث

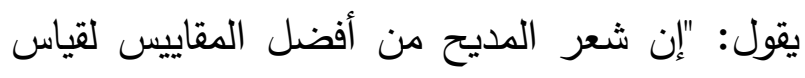

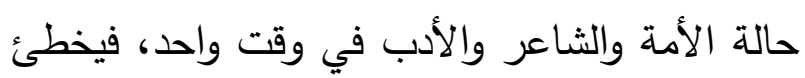

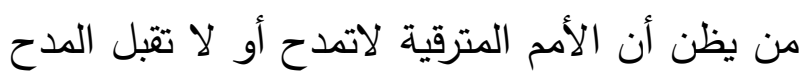

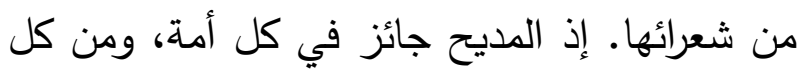

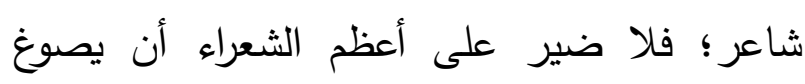
القصيد في مدح عظيم يعجب به ويؤمن بمناقبه، ولا

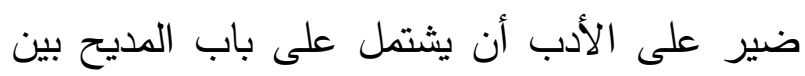

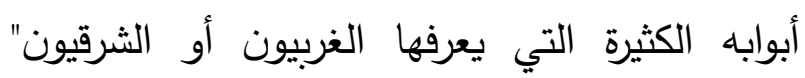

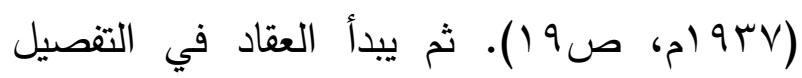

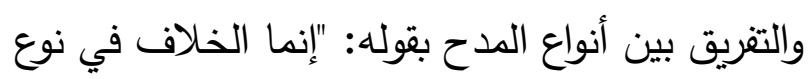

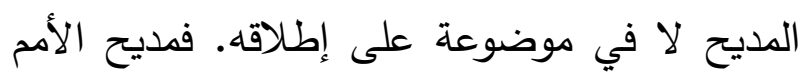

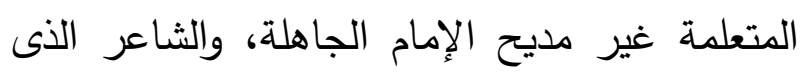

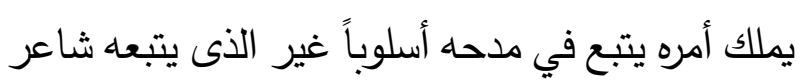

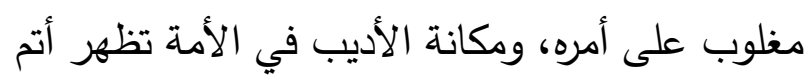

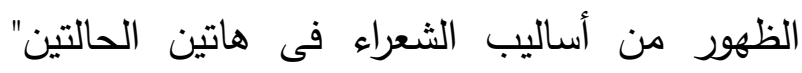

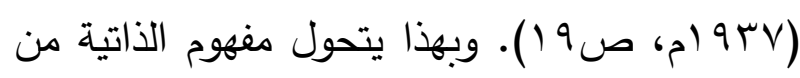
حديث الثاعر المادح عن نفسه إلى حريته في اتباع الأسلوب الذي يناسبه في المديح. ويربط العقاد في هذا السياق بين مكانة الأدب في الأمة وطبيعة قصيدة

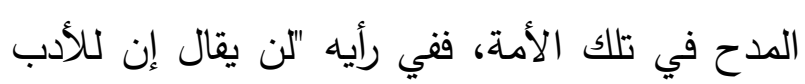

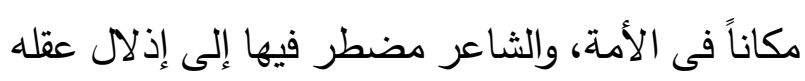

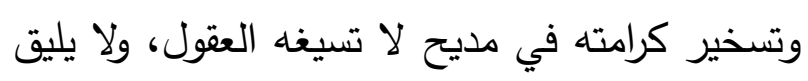

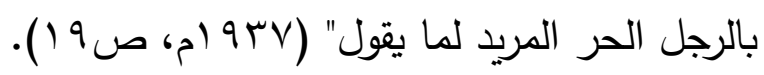


الممدوح من نفسـه، فيغلو في الثناء عليها فيبدو له كأنه يسخر منه، وينبه إلى نقائصه وعيوبه" (فرنسيس باكون، سا • rم، ص (V). فعلى الرغم دن الملق الظاهر في مثل هذا المدح إلا أنه قد يدفع الممدوح إلى رؤية عيوبه وتهذيب سلوكه. في المقابل، فقد "يصدر بعض الثناء من نية حسنة ومقصد شريف، كالثناء على الملوك والعظماء، وربما كان القصد به التعليم والإرشاد من طريق الإطراء والمديح" (فرنسيس

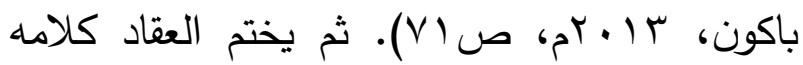
بقوله: "المدح المعتدل في مناسباته ومعارضه يفيد

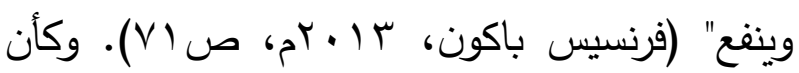
المدح -في رؤية العقاد- مدخل من مداخل النفس التي يستطيع الموجه والناصح من خلالها الولوج إلى لى نفس الممدوح ليقدم لله التوجيه والنصح. وكرر العقاد الإشارة إلى البعد النفسي للمدح في كتابه الشيخ الرئيس ابن سينا الذي نشره عام 7 ؛ 9 ام (الثيخ الرئيس، 7 9 (م)، وجعل فيه المدح الصادق والصادر عن إعجاب بالممدوح مقدماً على ذلك النوع من المدح الذي يتكسب فيه الشاعر بقصيدته؛ لأن النوع الأخير -في رأي العقاد- لا يعكس شخصية مؤلفه بقدر ما يصور شخصية الممدوح. فقد أُعجب بشعر ابن سينا؛ لأنه "جاءته في شعره مزية غير مقصودة: وهي أنه استغنى عن التكسب به أو عن نظمه في الأغراض المفتعلة، فكان ينظمه فيما يحسه من أحوال حياته، وكان شعره كله دالًّ عليه في مختلف حالاته، مطبوعاً بطابع مزاجه ودخيلة شعوره، متصلاً
تعكس هذه الآراء التي تبنّاها العقاد حول قصيدة المدح بعد الخروج من السجن نظرة متسامحة مع هذه القصيدة، فالمدح كغيره من أغراض الوصف والغزل والحماسة، وكل الأمم المتقدمة تمدح في شعرها، والشاعر المتكسب كالفنان الذي يتكسب بريشته، فالعبرة بالفن ذاته وليس الهدف منه. ولكن المهم -في رأي العقاد- هي مبادئ: الصدق في التعبير عن الإحساس والمشاعر، والذاتية، والحرية. فلا بد أن يكون المادح صادقاً في مدحه ومؤمناً بما يقول، وأن تبرز شخصيته في ذلك المديح، وأن يكون حراً في مدحه وليس مضطراً إليه. وكل هذه المبادئ تسير في الاتجاه الرومانسي الذي يُصنَّف ضمنه العقاد. وقد تطور موقفه من المدح في مرحلة لاحقة ليركّز على ثنائية النفس والمجتمع. ويمكن ربط هذه المرحلة بانتهاء الحرب العالمية الثانية، وعودته إلى مصر بعد أن خرج منها إلى السودان خائفاً من بطش القائد الألماني روميل (ت.ع؟ أم) وجنده بعد انتقاده الشديد لقائدهم هتلر (ت.0 ؛ 9 (م) في كتابيه هتلر في الميزان والنازية والأديان اللذين نشرهما عام • ع ام

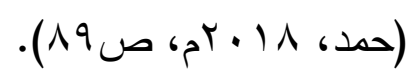
تقدم العقاد خطوة في قبوله لقصيدة المدح حين تحدث في كتابه فرنسيس باكون الذي ألفه عام 9 أم

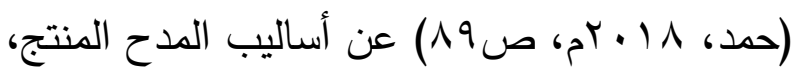
وعن ضروب المدح والملق الضارة بالمجتمع. فحين يستولي الكبر على المدوح فإن المادح -في رؤية العقاد- قد "يعمد إلى مواطن الضعف التي يحسها 
المتكبر ليعرف عيوبه، وقد يُستخدم مدح الملوك لتقديم النصح والإرشاد لهم، فالمدح المعتدل مفيد للمدوح والمجتمع. ويفضل العقاد -في هذه المرحلة- الشاعر الصادق الذي لا يتكسب بشعره على غيره؛ لأن شعره يدل على شخصيته أكثر من شعر المتكسبين بالمدح. وكأن العقاد يقف موقفاً وسطاً بين رفضه للتكسب بالشعر في مرحلة ما قبل سجنه وتسامحه مع هذه الشكل من أشكال التكسب في مرحلة ما بعد خروجه من السجن. ومع أن ملامح تأثر العقاد بالفلسفة الرومانسية الاجتماعية في رؤيته لقصيدة المدح بدأت مبكراً من خلال إثارته إلى ارتباط المدح بالأمة الماتها والمجتمع في آرائه المنشورة في المرحلتين السابقتين إلا أن المتأمل في رؤيته لقصيدة المدح في مرحلة ما بعد الحرب العالمية الثانية يجد أنها قربية -إلى حد كبير - من تلك الفلسفة التي تمزج بين الرؤيتين الرومانسية والاجتماعية من خلال مفاهيم عامة كالأمة والمجتمع والسياسة والدين. فالمدح -في رأي العقادقد يكون وسيلة لتحقيق الوئام بين السلطة والمجتمع، كما قد يكون وسيلة لإصلاح السلطة والرقي بالمجتمع. ونشر العقاد -بعد أن بلغ الستين من عمره- ديوانه بعد الأعاصير (عويضة، ؟ 99 (م، ص VV)، وقدّم له له بمقدمة عنونها ب"في ذمة النقد" أشار فيها إلى بعض آرائه النقدية التي دافع فيها عن قصيدة المدح، حيث كرر رفضه لوصف شعر المدح بالشعر التقليدي قائلاً: "وسمعوا كذلك أن المديح تقليد لشعر الصنعة الذي ننعاه على الأقدمين فخيل إليهم أن المديح كله باب
بأسلوب تفكيره وطريقته في النظر إلى الأمور" (الثيخ

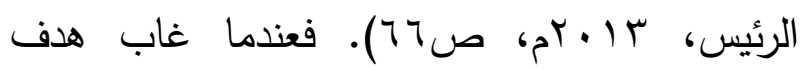
التكسب بالشعر عن ابن سينا وهو يكتب قصائده حضرت شخصيته في شعره، وتلك مزية في رأي العقاد وغيره من الرومانسيين.

وسلط العقاد في كتابه الذي نشره عام 900 ام بعنوان الشيوعية والإنسانية في شربعة الإسلام (حمد، 1 ( • أم، ص. •9) الضوء على الوظيفة الاجتماعية لشعر المدح في سياق تحليله للعلاقة بين موضوعات الأدب والماركسية؛ ليؤكد فائدة شعر المدح بقوله: "إن الممدوحين يُمدحون بالكرم والثجاعة، وليس الكرم فائدة مقصورة على الممدوح، وليست الشجاعة كذلك فائدة مقصورة عليه، وبخاصة في العصور التي يتكفل فيها الفرسان بالدفاع عن الأوطان" (الشيوعية

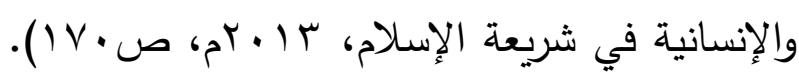
ثم يردُّ على الذين يرون أن الشعر العربي -بأغراضها المختلفة- شعر غنائي لا يعكس أطوار المجتمع كما تفعل الملحمة والشعر التمثيلي بقوله: "من المعلوم أن الشعر الغنائي يتناول المديح، وهو كبير الدلالة على شؤون الرئاسة في الأمة" (الشيوعية والإنسانية في

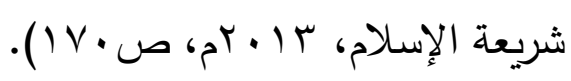
ويُستخلص من هذه الآراء التي سجلها العقاد في مؤلفاته المنشورة بعد الحرب العالمية الثانية أن النزعتين النفسية والاجتماعية بدأت تسيطر على رؤيته لقصيدة المدح ووظيفتها. فقد تكون هذه القصيدة وسيلة للولوج -بطريقة غير مباشرة- إلى نفس الممدوح 
لا يعنى أحداً غير السيد المدوح والثاعر المادح، ولا فائدة فيها لأحد بعد ذلك غير كاسب المدح وكاسب العطاء. وليس أظهر من هذا الوهم عند أقرب نظرة؛ فإن قصيدة المدح لو كانت كذلك لما استحقت من

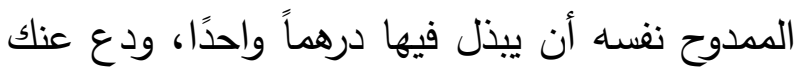
المئات والألوف مما يذكره الرواة في أحاديث الجوائز

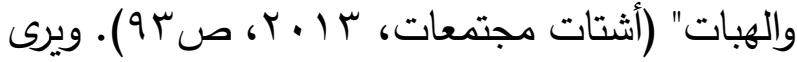
العقاد في مبالغة بعض الممدوحين في إكرام المادح إثارة إلى الدور الاجتماعي الإيجابي لقصيدة المدح

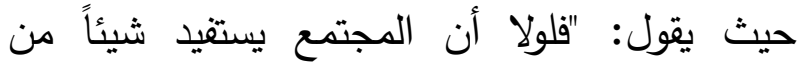
القصيدة، ويحفظها لهذه الفائد؛؛ لما احتفى بها المدوح، ولا جاشت بها ملكة التعبير في الثاعر"

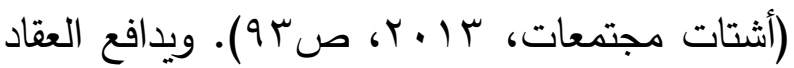
في أشتاته عن الثاعر المادح، وعن الدور الاجتماعي لشعر المدح، ويسخَر من الرافضين لذلك الشعر بقوله:

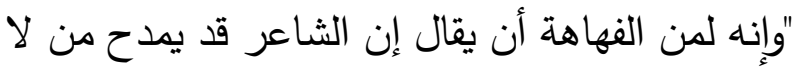

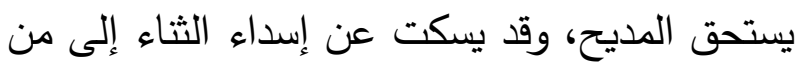
يستحقه، فهكذا يمكن أن يقال عن الخطأ والانحراف في تطبيق القانون، ولا يقول أحد من أجله بإلغاء

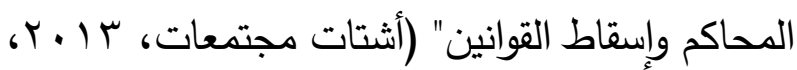

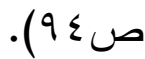
وسلط العقاد الضوء في كتابه رجال عرفتهم الذي نشره

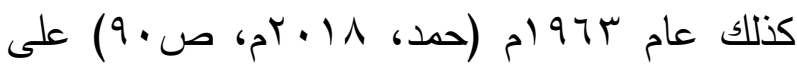
مرحلة جديدة لتطور قصيدة المدح. فقد تطورت تلك القصيدة بتطور وتغير نفسيات الممدوحين، حتى جاء القرن العشرين الذي أصبح فيه الملوك والأمراء مولعين
قديم لا يطرقه الشعراء المعاصرون" (90 (م، (19.

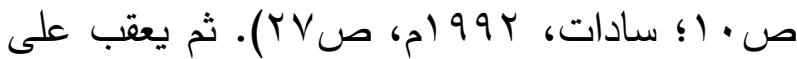

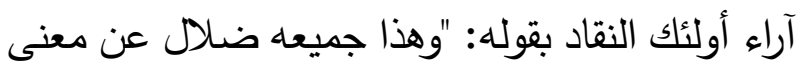
النقد فى الأدب الحديث. فالثاعر العصري يعاب على تغنيه بالناقة والطلل إذا كان غرامه بها حكاية للأقدمين

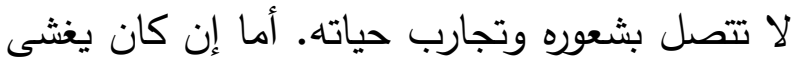
الصحراء ويركب الإبل ويقف على أطلال الهياكل فالتجديد العصرى يدعوه إلى النظام فى هذه الأغراض

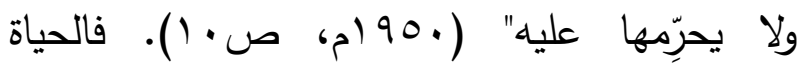
الاجتماعية -في رأي العقاد- هي التي تحدد إن كان الثاعر الذي يصف الناقة في طريقه إلى المدوح مقلداً أم مجدداً. واستمر موقف العقاد المؤيد لقصيدة المدح في كتابه أشتات مجتدعات في اللغتة والأدب الذي كتبه عام

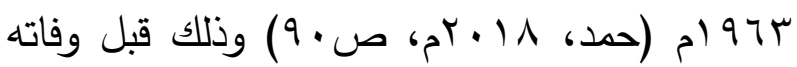
بعام، وأكد فيه فكرة الربط بين طبيعة المدح والحالة الاجتماعية بقوله: "ولا ريب أن وظيفة الأديب تتمثل لنا من مقدار تعويله على المدح والذم في تحصيل رزقه، ومن مروءته أو سقوط مروءته في التوسل

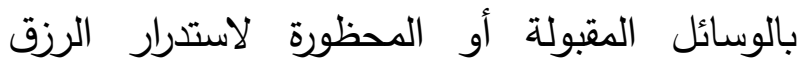
واستخفافه من الممدوحين، جزاء للبلاغة والإجادة وحسن التقدير ، أو خوفاً من البذاء وحياءً ممن لا يبالي

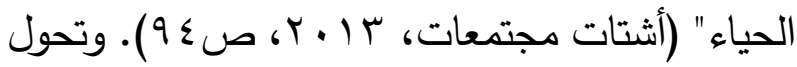
العقاد في هذا الكتاب إلى الدفاع عن المدح بوصفه شعراً مفيداً للمادح والمددوح والمجتمع، وعبَّر عن هذا المعنى بقوله: "قد يبدو للمتعجل أن قصيدة المدح كلام 
ليست حكراً على القدماء، وأن الدكافأة التي يحصل عليها الثاعر المادح تدل على قيمة التصيدة، وأن احتفاء الممدوح بها دلالة على دورها السياسي

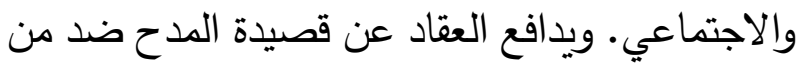
يتهمها بأنها تعتد على المبالغة والكذب بأنها مثل

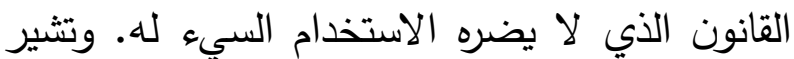
هذه الآراء إلى انفتاح العقاد -إلى حد ما- على الروية الكاية الكلاسيكية لقصيدة الددح بعض رفضها سابقاً. إن المحلل للآراء السابقة حول قصيدة الددح سيجد أن العقاد -في الغالب- لا يرفضها، ولا يقبلها قبولاً مطلقاً،

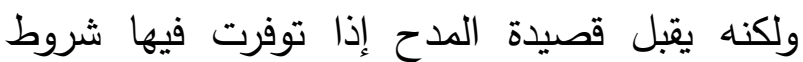
محددة، والتزمت بحدود ترتبط في المجمل بالفكر الرومانسي من مثل الذاتية، والفصل بين الأدب والأخلاق، وحرية الثاعر ، وصدق مشاعره وأحاسيسه أكثر من ارتباطها بشكل النص ولغته. وتعكس آراء العقاد حول قصيدة المدح في مراحل حياته المختلفة نزعة رومانسية اجتماعية تبرز من خلال اهتمامه بالوظيفة الإصلاحية لهذه القصيدة ودفاعه عن دورها في خدمة الأمة والمجتمع. فقد تُتخدم لتحقيق الوئام بين المجتمع والسلطة وتتديم النصح -غير المباشر - لهائ للملوك والسلاطين، خاصة إذا كان المديح معتدلاً.

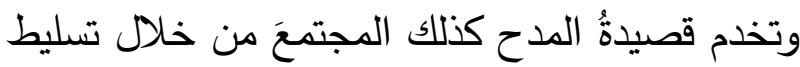
الضوء على الصنات الحسنة في الممدوح ليكون قدوة

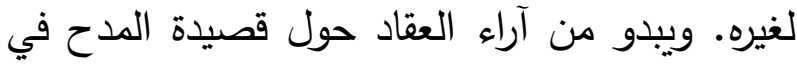

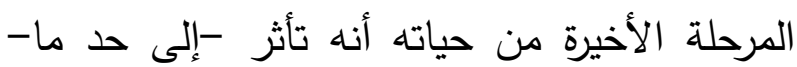
بالرؤية الكلاسيكية للقصيدة مع التزامه بأفكاره
-كما يقول العقاد- بأسلوب نظم التواريخ بعدد الحروف المعروفة بتواريخ، وقد كان هذا الأسلوب في

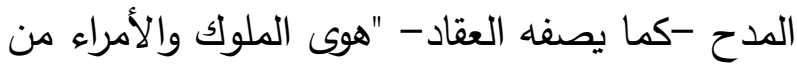
شعر الدديح لتسجيل أوقاته ومواعيده" (رجال عرفتهم، لهاه

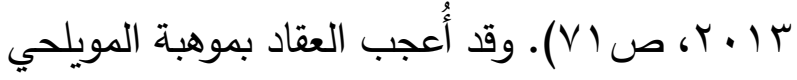
في هذا الفن حيث يقول: "فلم ينظم شاعر من هذا الفن قصيدة تضارع قصيدة المويلحي الكبير التي

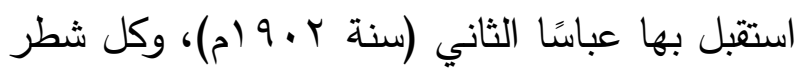

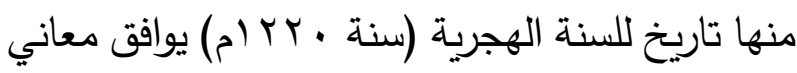
الكلمات في غير تكلف ظاهر يقتضيه التوفيق بين

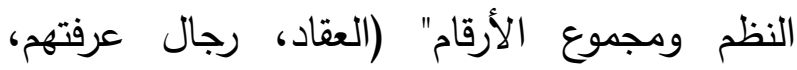

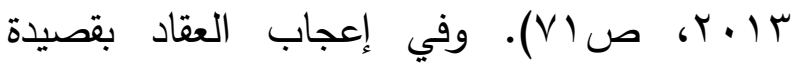
المويلحي -مع اعتمادها على أسلوب النظم الذي يخلو من العاطفة وينافي فكرة التعبير عن ذاتية الثاعر ومشاعره- دلالة غير مباشرة على مدى التسامح الذي لئي وصل إليها العقاد في مواقفه الأخيرة من شكل ومضمون قصيدة المدح. إن الموازنة بين آراء العقاد حول قصيدة الددح في المرحلة الأخيرة من حياته بعد بلوغه الستين والمرحلة الكان الأولى قبل دخوله السجن في مطلع الثلاثينيات من عمره تدل على أنه راجع كثيراً من مواقفه السابقة حول تلك التصيدة. فبعد رفضه لوقوف شوقي على الطلل

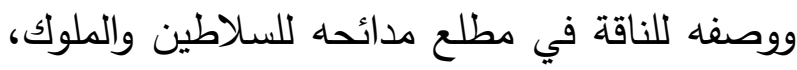
يبرر العقاد لبعض الثعراء المعاصرين ممن عرفوا الناقة والصحراء وقوفهم على الطلل في مدائحهم معتبراً أن ذلك لا ينافي التجديد. ويرى العقاد أن قصيدة الددح 
لدم يـا إمــام العـرب مشتملاً بـالمـلك في عـز وإقبـــال

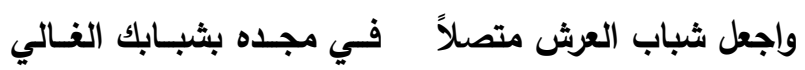

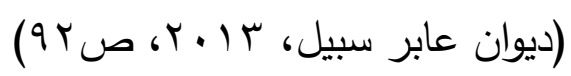
وكتب أكثر من قصيدة في مدح الملك فاروق، ومدح الملك عبد العزيز (ت.بهو (م) خلال زيارته لمصر ملحر عام 9 ام بقصيدته "أسد العرين" (العقاد، (د.ت)، ص00). والثابت في كل هذه القصائد أنها تلتزم في شكلها بالأوزان الخليلية والقافية، ويبقى مضدونها قابلاً للتحليل في ضوء الآراء ذات الطابع الرومانسي الاجتماعي التي اقترحها العقاد في مؤلفاته حول قصيدة المدح. ومن خلال تحليل موجز لقصيدة (غيث الصحراء) بوصفها أنموذجاً لقصيدة مدح السلطة في دواوين العقاد يتضح مدى التزامه في تلك القصيدة التي ألفها في مرحلة مبكرة من علاقته بالملك فاروق بالحدود والثروط الخاصة بالمدح التي نادى بها في مؤلفاته النقدية. وقد كتب العقاد قصيدته حين كان يمثل دائرة الصحراء بمجلس النواب، وألقاها أمام الملك فاروق في رحلته إلى صحراء مصر الغربية عام ربو ام

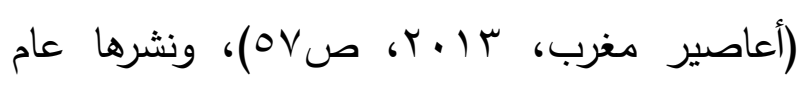

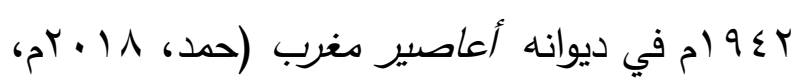
ص9^1)، وهو ما يشير إلى أنه كان راضياً عن القصيدة -على الأقل - حتى ذلك العام الذي نشرها فيه. وتمثِّل هذه القصيدة مرحلة انتقالية في حياة العقاد من مرحلة متوترة في علاقته بالسلطة قبل سجنه إلى في المراحل الأخيرة من حياته بعد الحرب العالمية الثانية.
الرومانسية. وإذا كانت أفكار التيار الرومانسي مؤثرة -إلى حد كبير - على رؤية العقاد الناقد لقصيدة المدح، فان التساؤل المرتبط بهذه النتيجة يتعلق بأسلوب العقاد الثاعر في قصائده التي يمدح بها الملوك والسلاطين ومدى الانسجام بين مدائحه ورؤيته النقدية للمدح. لقد تعددت قصائد المدح في دواوين العقاد وتعدد الممدوحون، كما ألّف العقاد قصيدة طويلة في المديح النبوي لم يتخلص فيها من الذاتية المرتبطة بالرومانسية، حيث خرج فيها عن المألوف من ختم القصيدة بالدعاء والتذلل وطلب شفاعة النبي -عليه الصلاة والسلام - ليختمها مفتخراً بذاته وشاعريته

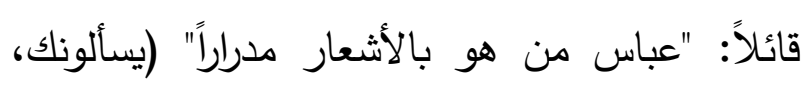

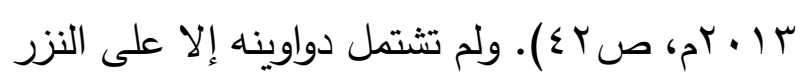
اليسير من القصائد والمقطوعات التي يمدح فيها الملوك والسلاطين، حيث مدح الخليفة عبدالحميد (ت.1/9 (م) بقصيدة يتيمة يهنئه فيها على إعلان الدستور، ويسجل فيها تاريخ السنة بحساب الحروف الأبجدية، ولم يسجل العقاد في كتبه إلا شطراً من القصيدة يقول فيه: "قد أنشأ الدستور عبد الحميد". وألفها لتوافق في مجموع حروفها بحساب الجمل السنةَ الهجرية التي أعلن فيها الدستور عام بrr اهـ (حياة

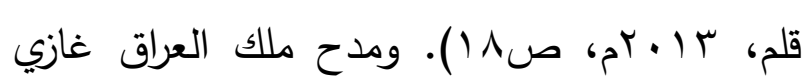
الأول (ت.9 9 (م) بقصيدة قصيرة يقول فيها:

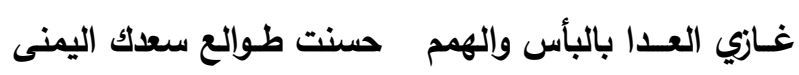

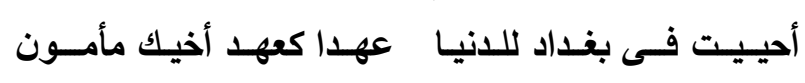

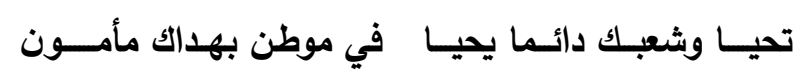


ثم في تصويره المددوح في صورة المؤمن بالله والمهتدي بهديه:

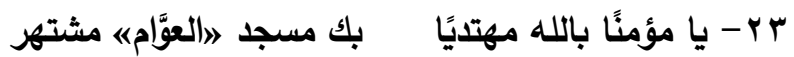
كل هذه الصفات تئكد أحقية الملك فاروق بملك مصر، وتتحض شكوك المشككين في سلطته، واستُخدمت بأسلوب يحاكي القصائد العباسية القديمة مثل قصيدة فتح عمورية لأبي تمام وغيرها. ولم يخرج العقاد -في الغالب- عن سنن القدماء في أوصاف المدح من مثل وصفه الممدوح بأنه جمع الثباب والإلهام والتبصر في الأمور • لقد كان الملك فاروق في الثامنة عشرة من عمره حين زار الصحراء، ومدحه العقاد بالقصيدة موضوع البحث. وقد جعل العقاد من عمر الممدوح مدخلاً لمدحه ووصفه بأنه جمع الشباب والحكمة كما جمع بين الإلهام وبعد النظر ، وقاد جيلاً شاباً يدعو للتفاؤل كما يقول الثاعر : بإن 11 - سبق الشباب به مراحلنا وأعـانــه الإلهــام والنظر

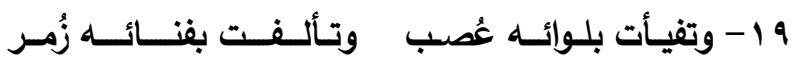

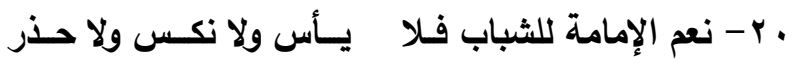

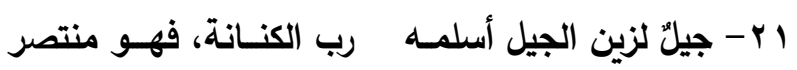
وكأن العقاد يرد على المشككين في قدرة الملك على إدارة الدولة بعد أن توفي والده وهو قاصر ، وعُيِتت هيئة وصاية على العرش حتى يصل فاروق إلى سن البلوغ. ويشير الثاعر إلى أن الملك مُلهَم وبعيد النظر ، والإلهام لا يرتبط بالعمر ، كما أن الشباب جعله متحمساً ليقود جيلاً جديداً إلى النصر ، وكلها معانٍ تقليدية لا تتضمن روح التجديد الذي نادى به العقاد.

\section{ثالثاً: تحليل قصيدة (غيث الصحراء)}

إن الباحث عن شخصية العقاد في مدحه للملوك بشكل عام- والملك فاروق -بصورة خاصة- لن يجد حضوراً بارزاً لتلك الشخصية، فلم يصور العقاد -في الغالب- مواقفه الشخصية في تلك المدائح، ولم يتحدث بصورة مباشرة عن نفسه، ولا عن علاقته بالمدوح. ولعل في الغياب شبه التام لضمير المتكلم وحضور ضمير المخاطب في تلك القصائد دلالة على أن العقاد لم يحرص في مدائحه على إبراز ذاته، ولم يتأثر في تلك القصائد برؤيته النقدية الرومانسية التي ترتكز على ذاتية الثاعر ، وإنما كان أقرب إلى الثاعر الإحيائي الذي يمدح الملك والخليفة بالكرم والشجاعة وغيرها من خصال المدح، كما يحاكي أسلوب الثاعر القديم في تأكيده على تديّن الممدوح والتزامه. فقد سار العقاد في قصيدته (غيث الصحراء) على نهج شعراء المدح القدماء في تصويرهم الممدوح في صورة المعتصم بالله والملتزم بأوامره والمجتتب لنواهيه، وكان لهذه الصورة في مدح الملوك والخلفاء بعدُ سياسي مرتبط بالاختيار الإلهي للمدوح ليكون خليفة الله، ويقيم شعائره في أرضده. وكرر العقاد استخدامه لهذه الصورة في أكثر من موضع في قصيدته (غيث الصحراء) من مثل قوله مادحاً الملك فاروق:

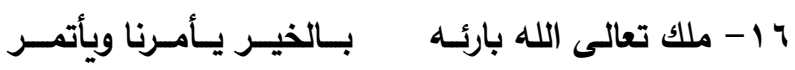
IV - مستعصم باللها معتزم مستمسك بـالحـق مقتـدر وكذلك في وصفه المدوح بأنه جمع فضيلتي العزم والشورى:

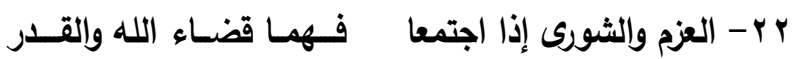


كما يستدعي العقاد العناصر ذاتها في تصويره رحلة الملك فاروق إلى الصحراء بطريقة تقليدية تستدعي صورة مشابهة في قول المتنبي:

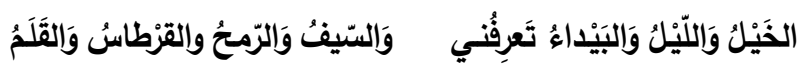

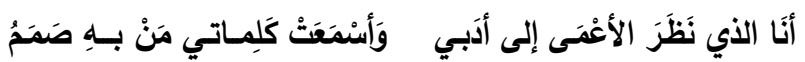

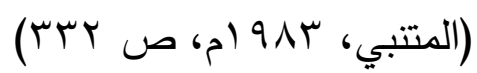

فيستخدم العقاد أسلوبي العطف واستدعاء حاسة البصر في بيتي المتنبي ليصف رحلة الملك فاروق

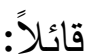

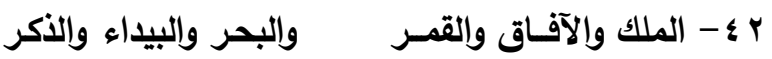

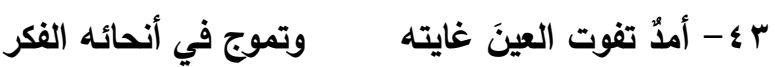
ثم يستمر في مدح الملك فاروق من خلال وصف طول الرحلة في الصحراء حيث يقول:

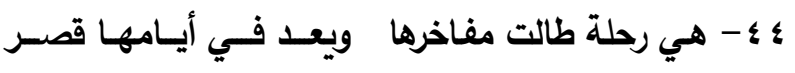

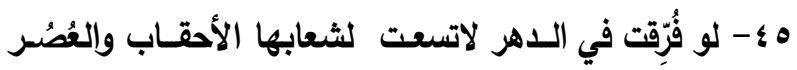
\ ؛ - في ساحة الفاروق يملأها ذخر الحياة، ويُحجم الخطر

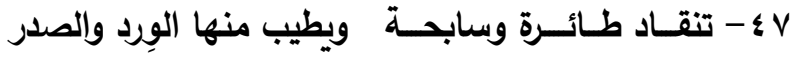
والمتأمل في تصوير العقاد للرحلة لا يجد فيه تلك المعاني والأساليب التجديدية التي دعى إليها في مؤلفاته. ومع أن رحلة الملك تختلف شكلاً ومضموناً عن الرحلة التقليدية إلا أن العقاد يستخدم صوراً تقليدية لوصف هذه الرحلة الحديثة. وأكد ذلك من خلال استخدامه للفعل "تنقاد" في البيت الأخير، وذلك في سياق وصفه الرحلة التي كانت بالطائرة والتطار

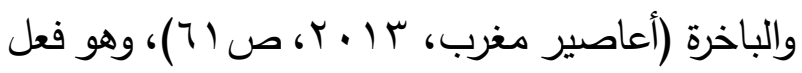
يستدعي لمخيلة القارئ صورة الناقة وهي تنقاد للشاعر في رحلته نحو الممدوح. ولم يخالف العقاد أسلوب المدح التقليدي في اعتماده على المبالغة في وصف وحف
وكما ارتكزت هذه الصور على الاستعارات والمجازات فقد استخدم العقاد أسلوب التشبيه في مدحه. يُعد التشبيه من الأساليب البلاغية التي ترتكز عليها قصيدة (غيث الصحراء)، ويستخدم العقاد هذا الأسلوب بطريقة تقليدية تنافي آراءه النقدية التي صور فيها الشاعر الذي يشبّه الممدوح بالشمس والقدر بالطفل الذي يشبّهه كل شيء بالسكر (9 ( • بم، صسr (1). فالملك فاروق يشبُه الغيث كما يقول العقاد: ه - كالغيث لولا سبق أنعمه والغيث يلحـق بعـده الثــر وهو يشبه النيل: צ- كـالنيل لـولا أن موسمه في كـل يـوم حاضـر نضر ويحاول الشاعر من خلال الاستدراك وأداته "لولا" في البيتين أن يضيف معنى يخرج بالتشبيهين من التقليد إلى التجديد من خلال إيهام المتلقي بأن ما سيأتي بعد "لولا" مخالف لما قبله. ويستخدم صورة مشابهة ولكن بأسلوب مختلف حين يخاطب القبائل قائلاً:

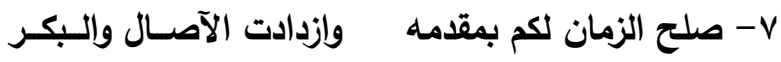
1- فاستبشروا بالخصب أجمعه لا جدب حيث النيل والمطر وكأن العقاد يسعى إلى تجديد صور المدح التقليدي من خلال الاستدراك والتفصيل بدلاً من ابتداع صور وأساليب جديدة تمثل آراءه النقدية ومذهبه الفكري. ويتبع العقاد في قصيدته أسلوب استدعاء عناصر الطبيعة في تشبيهاته ومدحه للملك فاروق من مثل التشبيهات الأخيرة المرتبطة بالنيل والمطر ، ووصفه للخيام بأنها تناطح السحاب في قوله:

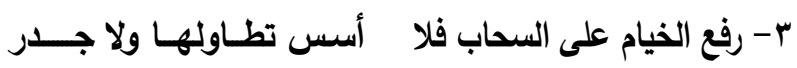


لقد جعل العقاد من علاقة الشعب -الممثل في القبائل- بالملك الممدوح مدخلاً رئيساً للمدح في قصائده التي يمدح فيها الملوك، وأسسها على ثنائية السلطة والشعب، فالممدوح يخدم الشعب والشعب يحب الممدوح. ويصور الشاعر علاقة الممدوح بالشعب والثعاب والقبائل في مطلع القصيدة من خلال استدعاء بعض وله عناصر المقدمة الطللية مثل حداء الإبل والبيداء قائلاً: 1- يا حادي البشرى دنا السفر نادِ القبائل حيثما انتشروا r- فاروق في البيداء يصحبها تيهوا بني البيداء وافتخروا ثم يشير إلى علاقة "الحب" التي تجمع الممدوح بالقبائل في قوله مخاطبياً القبائل: 9 - أحبيتموه على السماع كما شاء الولاء ، وشاعت السير ويمدح قبائل الصحراء ويثني على ولائهم للمدوح بقوله:

اس - أصغي فأسمع في جوانبها هزجًا يشيع بها، وينحصر

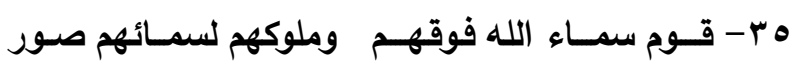
جس - إن يذكروا بالحمـد راعيهم فهم الرعاة، وهكذا فُطروا

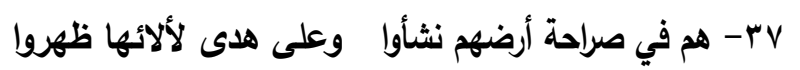

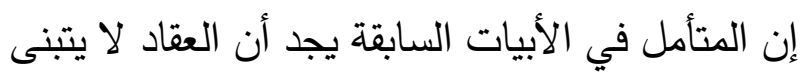

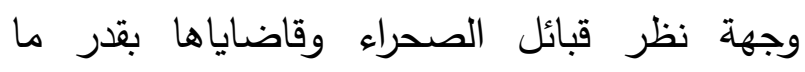
يستخدمها وسيلة للثناء على الممدوح، ولا يستخدم المدح وسيلة لإيصال صوت القبائل إلى السلطة وإنما ليؤكد للمدوح أن القبائل راضية عنه. وفي مقابل الثناء على الملك فاروق باسم الثعب، يصور الثاعر احتفاء الشعب بالملك، وتغنيّهم بفضائله قائلاً:

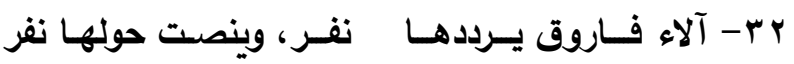
وكأن القبائل تجتمع في مجالسها ليردد بعضها فضائل الممدوح في الوقت الذي ينصت فيه الآخرون. ويشير
لجأ العقاد إلى المبالغة في مدحه للملك فاروق مع أنه دعا إلى تجنب أول عيب من العيوب التي أدت إلى هبوط الشعر العربي وهو "المبالغة والشطط" (مطالعات

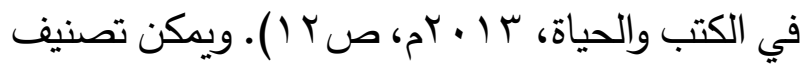
المبالغات في قصيدة (غيث الصحراء) إلى مبالغات تقليدية من مثل وصفه الملك بقوله:

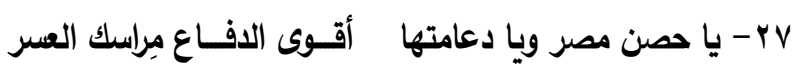
1 r - يا شاهد التاريخ في أثر العين أنت، وما مضى أثر

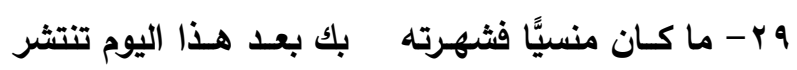
وتتضمن القصيدة شكلاً آخر من المبالغات التي يمزئه

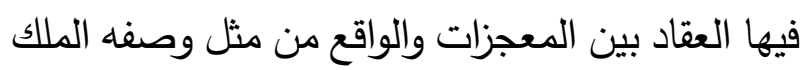
بقوله: ه ץ - يا جاعل الملح الأجاج روى بيديك طاب الملح والصبر وتشبيها الممدوح بعيسى عليه السلام قائلاً: ج ب - يا شافي المرضى وكافلهم عيسى على كفيك مستتر فالثاعر يشير في البيتين بطريقة غير مباشرة إلى

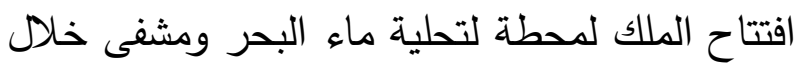

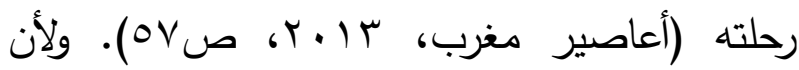
النص لا يتضمن إشارة إلى هذين الحدثين التاريخيين؛ فقد جاءت الصورتان على طريقة المبالغة المفرطة. وكرر هذا الأسلوب في إثارته إلى افتتاح الملك لمصنع النسيج بقوله: ـ ا - يا نسج وحدك في مآثره بيديك زين القطن والوبر وما يبرر استخدام المبالغة في هذه الصور أنه لو أشار في هذه الأبيات الثلاث إلى الحدث التاريخي كافتتاح مصنع النسيج وغيره لتحولت تلك الصور إلى مجرد إشارات لأحداث تاريخية، ولعجزت تلك الصور عن وعن إلى التعبير عن ما فعله الممدوح لخدمة الشعب والقبائل. 
العقاد أن يوفِّق بين وظيفته بوصفه ممثلاً لدائرة الصحراء بمجلس النواب من جهة واتجاهه الفكري بلني

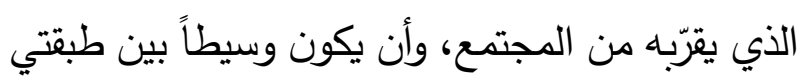
السلطة والمجتمع على طريقة البلغاء في الإمبراطورية

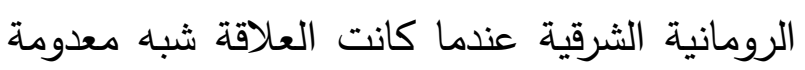
بين القصر والطبقة العليا القريبة من السلطة من جهة والطبقة الدنيا من المجتمع من جهة أخرى. وكان الأدباء -كما يؤكد بيتر براون- يستخدمون مهاراتهم

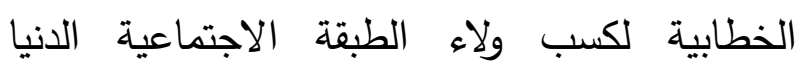
للإمبراطور الذي كان يشعر بنقص الولاء بين أفراد

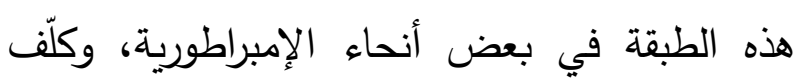
الأدباء بجبر هذا النقص من خلال القوة الناعمة

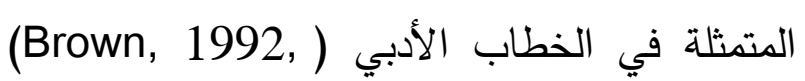

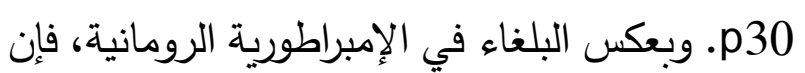

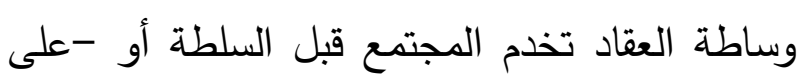
الأقل - تخدم الطرفين.

إن البحث في المستوى العميق لنص (غيث المبن الصحراء) يكثف عن رسائل غير مباشرة تتعلق بطبيعة العلاقة بين المجتمع والسلطة، وقد مهّد العقاد

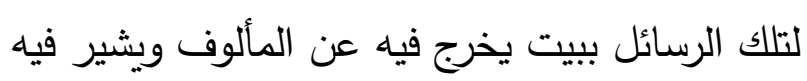
إلى نفسه بقوله:

• ب- إني إلى الصحراء ملتفت وعلى فـم الصحراء منتظر

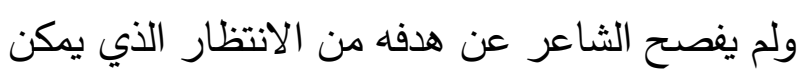

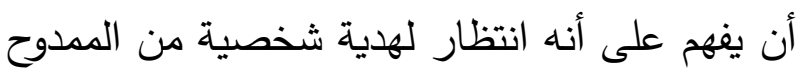

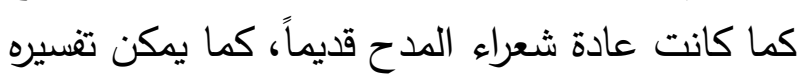
بأن الثاعر ينتظر - -بوصفه وسيطاً بين القبائل والسلطة- أن يُظهر أبناء القبائل فرحتهم بالملك، ويرد
الثاعر إلى إنشاد أبناء القبائل لفضائل المدوح وهم على جمالهم قائلاً: ؟ ؟ب- يهفو النزيل لها وينثدها سارون فوق جمالهم سهروا

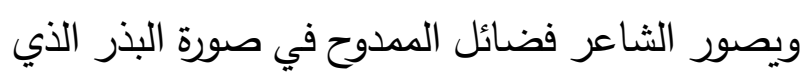
ينبت وينمو كالشجر قائلاً:

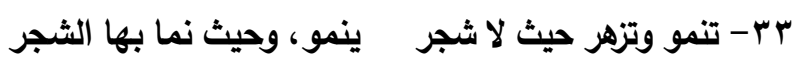

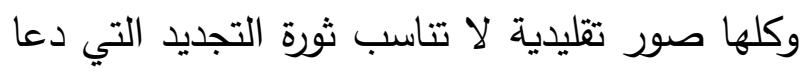

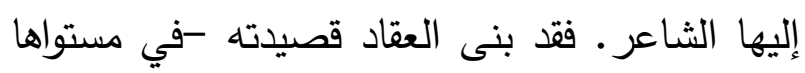

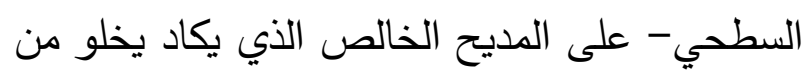
التعبير عن الإنسان ومشاعره. خالفت قصيدة العقاد (غيث الصحراء) كغيرها من الصنان مدائحه للملك فاروق كثيراً من آرائه الفكرية والنقدية حول المدح. وقد دفع هذا التناقض في رؤية العقاد

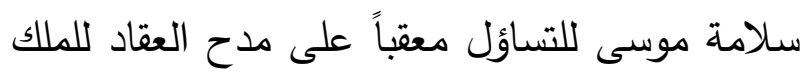

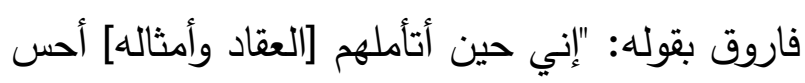
أني ظلمت شوقي: فإنه قد نشأ على أعتاب القصور

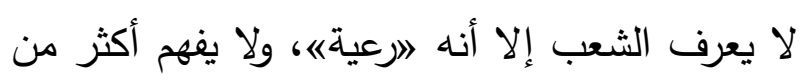

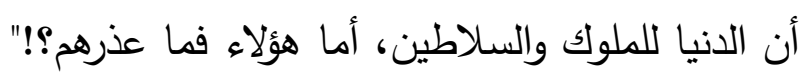

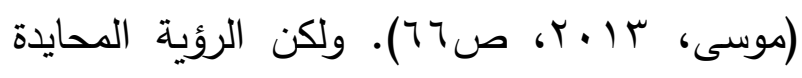

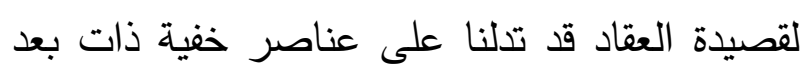

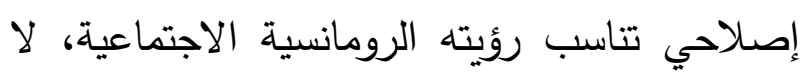
يدركها إلا القارئ الذي يتجاوز ظاهر النص ليبحث

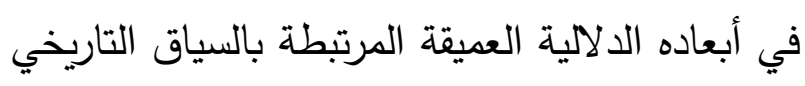
للنص. ومع الغياب المباشر لشخصية العقاد في قصيدته

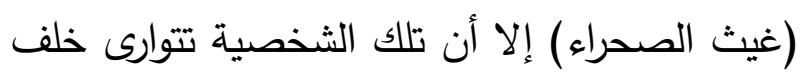
مفهوم "الوسيط" بين المجتمع والسلطة. فقد حاول الأ تلوارئ 
المكانة، أي إلى بذل ماء الوجه" (ستيتكفيتش،

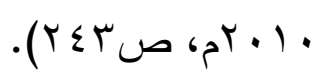

وكي تكتمل وساطة الثاعر بين السلطة والقبائل فعلى كل طرف من هذه الأطراف الثلاث أن يؤدي دوره. فقد قدَّم الشاعر مدائحه للملك، واستجابت القبائل لتلك

$$
\text { المدائح وتغنت بها كما يقول الشاعر : }
$$

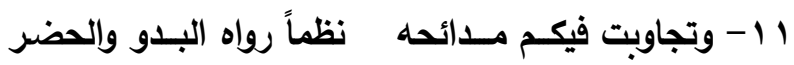
وأكّد الشاعرُ صدقَ القبائل في تغنيها بمدائح الملك بقوله:

r ا إلعرب أصدق ما سمعت إذا غنوا على البيداء أو شعروا وبعد أن قدّم أبناء القبائل واجبهم، وقدم الشاعر قصيدته التي تقوم مقام الهدية، فعلى الممدوح أن يرد على هذا الاحتفاء والإهداء بإهداء مقابل من خلال تقديم العون والمساعدة للقبائل لتكتمل الوساطة. وقد أشار الثاعر إلى تفاؤله بكرم الممدوح في قوله مخاطباً القبائل:

با - فالآن فاكتحلــوا بطلعتــهـ وتيـمنـوا باليمـن وابتــروا ثم يؤكد الشاعر ثقته في الملك حين يساوي بين حاستي السمع والبصر ، فإذا كانت القبائل تسمع عن كرم الملك فإنها ستبصر هذا الكرم:

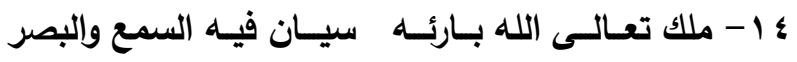
وإذا كانت تسمع أقوال الملك، فإن أعماله تلازم أقواله: 1 - لم يختلف قول ولا عمل مــــه، ولا خُبــر ولا خَبـر فالشاعر يتكسب بقصيدته، ولكنه لا يتكسب لنفسه كعادة جل شعراء المدح، وإنما يتكسب لقبائل الصحراء. واختار لفظ "البشرى" في مطلع قصيدته حين يقول: "يا حادي البشرى دنا السفر"؛ ليؤكد
الملك على ذلك بمساعدة القبائل. فقد شكلت القبائل مكوناً مهماً من مكونات الشعب، وكان ولاؤهم سبياً في الاستقرار كما كان تمردهم سبباً للاضطرابات والفتن. ويمكن في هذا السياق فهم وصف الثاعر لهم بالصدق في قوله: 1 ب- بلغاء ما عرفوا السطور على غير الرمال، وعاش ما سطروا بأنه تذكير للملك بصدق القبائل في ولائهم، وأنهم مصدر قوة لمن يكسبهم، خاصة بعد معاناتهم وصبرهم الذي وصفه الشاعر بقوله: q r- حرمتهم الأيام فاصطبروا ومتى أصابــا نعمة شكـروا فهم صابرون على فقرهم وبؤسهم، وسيشكرون النعم والعطايا التي تمنح لهم. ويكرر الشاعر تذكيره للمدوح بضرورة كسب ولاء القبائل بطريقة غير مباشرة وذلك

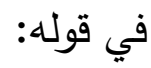
• ـ - فاروق قبلتهم إذا رحلوا وإليسه موئلهم إذا حضـروا فولاؤهم للممدوح قوي، ولكنه مشروط بما جاء في البيت التالي حيث يقول الشاعر:

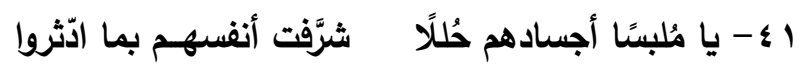
واستخدام صيغ اسم الفاعل والفعل الماضي في هذا السياق المرتبط بطلب المساعدة يشكل تحدياً للمددوح الذي يُلزمه العرف القبلي أن يَرد هذا الاحتفاء بإكرام القبائل؛ لأن هذا العرف يقوم على فكرة رد الجميل بمثله، وهو بذلك يشبه التبادل الطقوسي في رؤية ماوس التي طبقتها ستيتكغيتش على قصيدة المدح، حيث إن "الفشل في إعطاء الهدية أو قبولها مثل الفشل في إعطاء هدية مقابلة لها، تؤدي إلى الحط من 
يكون العقاد قصد الإصـلاح والتعليم والإرشاد في ثنائه على الملك فاروق على الطريقة التي ذكرها في كتابه فرنسيس باكون عندما قال: "يصدر بعض الثناء من نية حسنة ومقصد شريف، كالثناء على الملوك والعظماء، وربما كان القصد به التعليم والإرشاد من

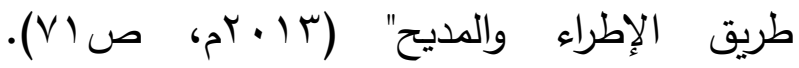
وتستدعي دراسة شخصية الشاعر خارج القصيدة البحث عن الهدف وراء مدحه الملك فاروق. إن السياق التاريخي لقصيدة (غيث الصحراء) يشير إلى أن العقاد ألقاها أمام الملك، فإن كان قد كتبها ليسعد الملك ولتكون فقرة من مناسبة في حفل افتتاح المنشآت وليثني على أفعال الملك دون نية الحديث باسم القبائل والتعبير عن معاناتها فإن القصيدة يمكن أن تُعد -إلى حد كبير - "انقلاباً" على مواقفه الفكرية والنقدية من قصيدة مدح السلطة. وإن كان قد رغب في التقرب من الملك من خلال مدحه، فذلك ينافي آراءه الفكرية ومواقفه النقدية التي انطلقت من فلسفة رومانسية اجتماعية. في المقابل، إن كان العقاد يحمِّل مديحه رسائل اجتماعية غير مباشرة تتعلق بحاجة القبائل للعون والمساعدة فإن القصيدة تنسجم -في مستواها العميق- مع كثير من آرائه حول قصيدة المدح. فقد يكون أراد أن يخدم المجتمع بمدائحه للسلطة من خلال وصف الممدوح بالكرم كي يكرم المجتمع، ووصفه بالشجاعة كي يحمي شعبه ... إلخ، ويكون العقاد بذلك قد استخدم وسيلة كلاسيكية (قصيدة المدح) لتحقيق غاية إصلاحية تتاسب فلسفته
للممدوح أن القبائل تتتظر كرمه، ويشر القبائل بقرب المساعدة من المددوح. ويُخفي هذا المدح ذو البعد التكسبي شكلاً من أشكال التحدي للمدوح ليثبت صدق الشاعر في مدحه، وصدق أبناء القبائل في تفاؤلهم بكرم المددوح. واستخدم الشاعر أسلوب المدح المباشر ليقنع الممدوح -من خلال وصفه بالكرم والجود - أن يساعد القبائل، مؤمِلاً أن يستجيب الملك للطلب رغبة في إثبات كرمه أو رهبة من اتهامه بالبخل والثح على شعبه. وعبّر عن هذا المعنى من خلال تصويره لترقب الجميع لقدوم الممدوح وانتظارهم لله قائلاً:

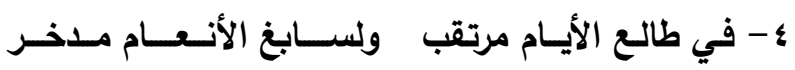

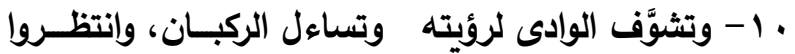
وكما انتظر الشاعر في قوله "وعلى فم الصحراء منتظر" (البيت · r)، فالقبائل تتتظر ، والوادي يتشوف لرؤية الممدوح. وكلها صور تعكس فرح القبائل بقدوم الممدوح، وبمقدار هذا الفرح تكون الحاجة إلى عطايا

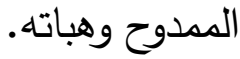
إن المنهج النفسي الذي يميل إليه العقاد (أفيون الشعوب، س | • بم، ص • (1) يرى أن دراسة شخصية الممدوح لا تقل أهمية عن دراسة شخصية المادح، وأن تأثير المادح على القصيدة لا يقل أهمية عن تأثير الممدوح. ومن هنا، فإن تسليط الضوء على شخصية العقاد سيقود إلى التفريق بين شخصيتين: شخصية العقاد داخل القصيدة وشخصيته خارجها. فالشاعر يبرز في القصيدة بوصفه وسيطاً بين الملك والقبائل، ويسعى إلى خدمة القبائل من خلال مدحه الملك. وقد 
0- لم يلتزم العقاد في قصيدته (غيث الصحراء) بجميع الشروط التي وضعها لقصيدة المدح في مؤلفاته الفكرية والنقدية.

7- أن قصائد العقاد في مدح السلطة تقبل القراءة بوصفها انقلاباً على أفكاره الرومانسية التي كان ينادي بتطبيقها في قصيدة المدح، وخروجاً على آرائه الاجتماعية التي اقترحها لتحقيق الوئام الاجتماعي. كما يمكن أن تُرَأ بوصفها وسائل لتحقيق غايات اجتماعية تتمثل في حصول المجتمع على حقوقه من السلطة كاستجابة لقصيدة المدح. - أن الانقلاب الذي تحدث عنه سلامة موسى في آراء العقاد عندما كان مع المجتمع في مطلع حياته وآرائه بعد ذلك عندما أصبح ملوكياً قريباً من السلطة

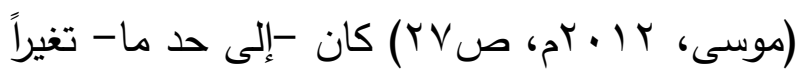
في أسلوب التعامل مع السلطة في كتاباته أكثر منه انقلاباً في المواقف؛ فقد تحول العقاد إلى أسلوب إقناع السلطة -بطريقة غير مباشرة- بدلاً من مواجهتها.

\section{المصادر والمراجع}

\section{اولاً : المراجع العربية}

أبو دية، أيوب عيسى (r (..rم)، عباس محمود العقاد: من العلم إلى الدين، عمان.

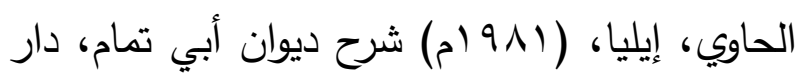

$$
\text { الكتاب اللبناني، بيروت. }
$$

حسن، محمد عبد الغني، (9V9 (م) عقاد وقضية الشعر ، الهيئه المصرية العامة للكتاب، القاهرة.
الرومانسية الاجتماعية (تحقيق الوئام بين طبقات (المجتمع).

\section{الخاتمة}

وبعد تتبع في ضوء المنهج التاريخي لمواقف العقاد من قصيدة مدح السلطة، وتحليل لإحدى مدائحه للملك فاروق عندما كان على رأس السلطة بوصفها أنموذجاً لمدائحه للملوك والسلاطين يمكن استخلاص عدد من النتائج، أهمها: - أهوا: 1- وضع العقاد شروطاً وحدوداً لقصيدة المدح تتقق -في المجمل- مع الاتجاه الرومانسي الاجتماعي الذي اتبعه. من هذه الشروط ما يتعلق بالشاعر ، ومنها ما يرتبط بصورة الممدوح، ومنها -كذلك- ما يخص السياق الاجتماعي. r- أن رؤية العقاد حول قصيدة مدح السلطة قريبة إلى حد كبير - من الفلسفة الرومانسية الاجتماعية، على الرغم من خروج بعض آرائه عن تلك الفلسفة واقترابها من الكلاسيكية. r- أن ما تضمنته مؤلفات العقاد من رفض لقصيدة المدح عند شوقي يمكن أن يفسَّر على أنه ليس رفضاً لقصيدة المدح على إطلاقه بقدر ما كان رفضاً لاتجاه شوقي فيها، ويمكن تصنيفه كأحد آثار الخصومة بينه

$$
\text { وبين شوقي. }
$$

ع - أن مواقف العقاد الرافضة لمدح السلطة في مرحلة ما قبل الخروج من السجن يمكن أن تُربط بشخصيته الثورية في بداية حياته السياسية وبتأثره العميق بالاتجاه الرومانسي الأوروبي في مطلع حياته الفكرية. 
- (T ا • Yم) حياة قلم، مؤسسة هنداوي للتعليم والثقافة،

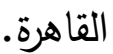

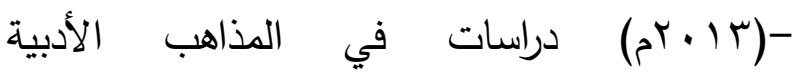
والاجتماعية، مؤسسة هنداوي للتعليم والثقافة، القاهرة.

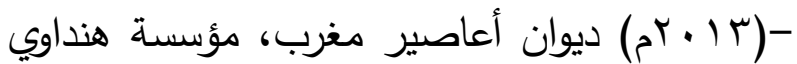
للتعليم والثقافة: القاهرة.

بيروت.

- (T ( • rم) ديوان عابر سبيل، مؤسسة هنداوي للتعليم والثقافة: القاهرة. - (الت

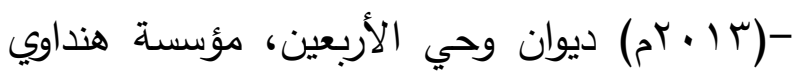
للتعليم والثقافة، القاهرة. -(TM • (Yم) رجال عرفتهم ، مؤسسة هنداوي للتعليم والثقافة: القاهرة. - (الت

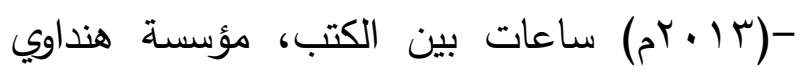
للتعليم والثقافة، القاهرة.

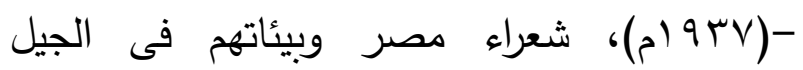
الماضي، نهضة مصر ، القاهرة.

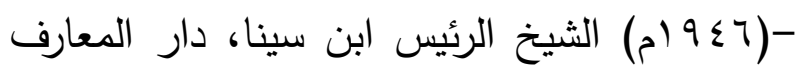
للطباعة والنشر ، القاهرة. - (T/ • بم) الثيخ الرئيس ابن سينا، مؤسسة هنداوي للتعليم والثقافة، القاهرة.

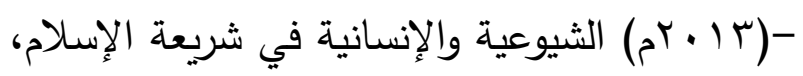
مؤسسة هنداوي للتعليم والثقافة، القاهرة.

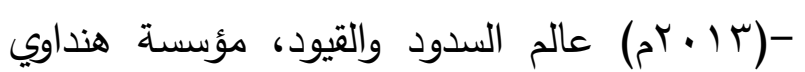
للتعليم والثقافة، القاهرة.
حدد، خليل، (1 ـ بم) الدقال الأدبى عند العقاد، دار حميثرا للنشر والترجمة، القاهرة. حمد، عبد الله خضر، (VV ( IVم) المذاهب الأدبية: دراسة وتحليل، دار القلم للنشر والتوزيح، بيروت. سادات، جيهان، (1992م) أثر النقد الإنجليزى فى النقاد الرومانسيين فى مصر ، دار المعارف، القاهرة. ستيتكفيتش، سوزان، ( • ( إم) القصيدة والسلطة: الأسطورة، الجنوسة، والمراسم في القصيدة العربية الكلاسيكية، ترجمة، حسن البنا عز الدين. القاهرة، المركز القومي للترجمة. السيد، فؤاد صالح، (10 (1) أعظم الأحداث المعاصرة ( . .9 1-ع 1 • r م)، مكتبة حسن العصرية، بيروت.

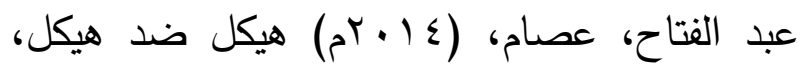
طץ، شركة الشريف ماس للنشر والتوزيع، القاهرة. العقاد، عباس محمود، والمازني، إبراهيم عبد القادر، (9 1 • rم) الديوان في الأدب والنقد، دار القلم، بيروت. العقاد، عباس محمود، (r/ • r م) ابن الرومي: حياته من شعره، مؤسسة هنداوي للتعليم والثقافة، القاهرة.

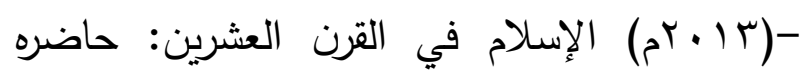
ومستقبله، مؤسسة هنداوي، القاهرة.

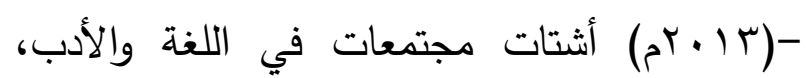
مؤسسة هنداوي للتعليم والثقافة: القاهرة. - (T/ • rم) أفيون الشعوب، مؤسسة هنداوي للتعليم

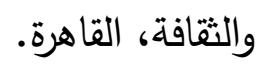
- (90 (م) بعد الأعاصير، دار المعارف، القاهرة. 
علوش، جميل، (1999) التجديد والحداثة بمعيار بياني، دار الحكمة للطباعة والنشر والتوزيع، القاهرة.

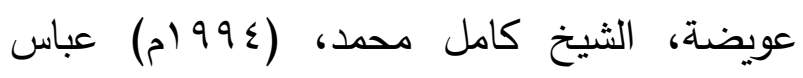
محمود العقاد: قطرات من بحر أدبه، دار الكتب

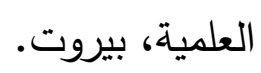

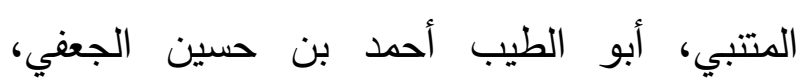

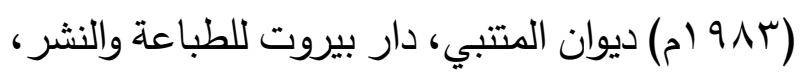

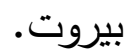

منصور ، أنيس، (r ( + rم) في صالون العقاد كانت لنا أيام، دار نهضة مصر، الئ، القاهرة.

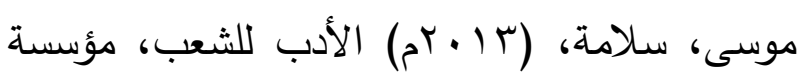
هنداوي للتعليم والثقافة: القاهرة.

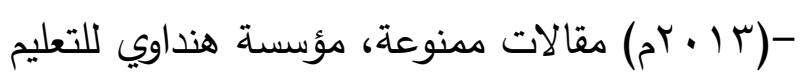
والثقافة، القاهرة.

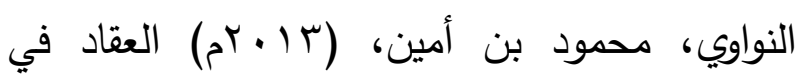

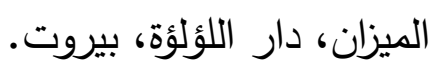

\section{المراجع الانجليزية}

Brown, Peter, Power and Persuasion in Late Antiquity: Towards a Christian Empire, (1992), University of Wisconsin Press, Madison.

Evans, David Owen. Social Romanticism In France 1830-1848, (1951), Oxford University Press, Oxford.

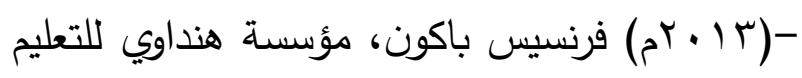
والثقافة، القاهرة.

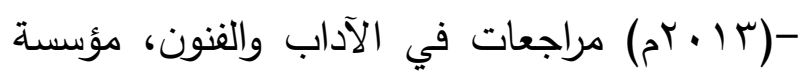
هنداوي للتعليم والثقافة، القاهرة.

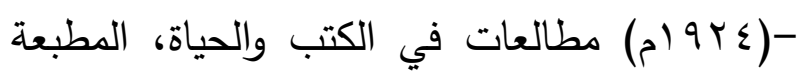
التجارية الكبرى، القاهرة.

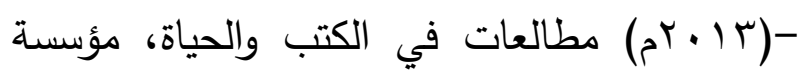
هنداوي للتعليم والثقافة، القاهرة. -(د.ت) مع عاهل الجزيرة العربية، منشورات المكتبة

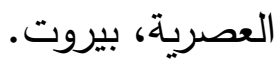

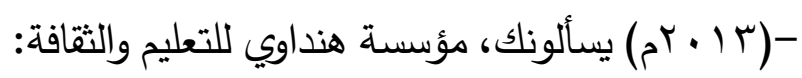

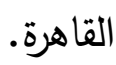
علوان، علي عباس، (9V0 (م) تطور الشعر العربي

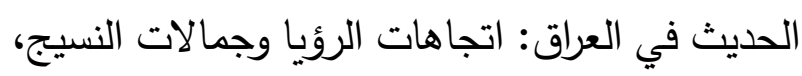
وزارة الإعلام، بغداد.

Ladd, Andrew; Jerry R. Phillips; Karen Meyers, Romanticism and Transcendentalism: 18001860, (2010), Chelsea house publishers, New York.

Mitzman, Arthur, "Romanticism and Revolution: the Vision of Jules Michelet," in Revolutionary Romanticism: A Drunken Boat Anthology, ed. Max Blechman, p-p 83-100, City Lights Books, San Francisco. 


\title{
The Literary Critical Vision on The Praise Poem by Al-'Aqqād: Between Theorization and Application
}

\author{
Mustafa Muhammad T Binmayaba \\ Associate Professor in Literary Criticism, \\ Department of Arabic Language and Literature \\ King AbdulAziz University, Jeddah, Saudi Arabia
}

\begin{abstract}
Aqqād's vision influenced by the romantic current about the connection between literature and the political power and elite -on one handand his literary practice of that vision, on the other. In light of an analytical historical approach, the research observes the changes of al-'Aqqād's attitudes towards praising of the political power and his method of composing that form of poetry. It argues that al-'Aqqād's attitudes towards praising the political authority follow, to large extent, the thoughts of the romantic current; however, he did not adhere to all the conditions and limits he set for poems that praise the political authority in his poetic praise to kings. Al- 'Aqqād's poem "ghayth al-șahrā" (Desert Rain) which was composed to praise King Fārūq during his visit to the Western desert in 1938 is chosen to be a model that transfers the analysis from theorizing to application and reflects the form and content of al-'Aqqād's poems that praise the political authority. This model also presents the extent to which al-'Aqqād's poems are affected by his romantic vision and reflects the extent of al-'Aqqād's commitment in his praise to the theoretical views on which he establishes his attitudes towards the poem that praises the political authority.
\end{abstract}

Key words: 'Abbās Mahmūd al-'Aqqād-the political authority-panegyric ode-King Fārūq- King Fu'ād the First- Romanticism-social Romanticim-Classicism 